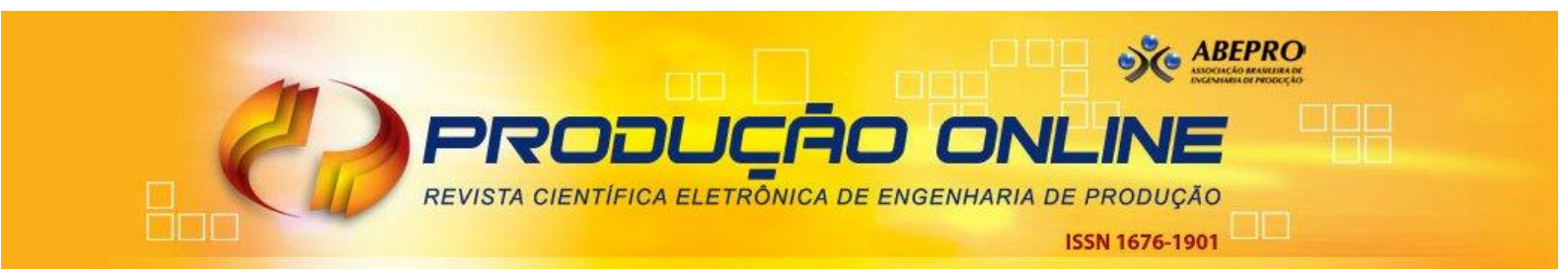

\title{
LOGÍSTICA REVERSA E IDENTIFICAÇÃO DE PRODUTOS: REVISÃO TEÓRICA PARA INDÚSTRIA ELETROELETRÔNICA
}

\section{REVERSE LOGISTICS AND PRODUCT IDENTIFICATION: THEORETICAL REVIEW FOR ELECTROELECTRONIC INDUSTRY}

\author{
Uanderson Rébula de Oliveira*E-mail: uanderson.rebula@yahoo.com.br \\ Fernando Augusto Silva Marins* E-mail: fmarins@feg.unesp.br \\ Jorge Muniz Júnior ${ }^{* *}$ E-mail: jorgemuniz@feg.unesp.br \\ * Faculdade de Engenharia do Campus de Guaratinguetá (FEG) - Universidade Estadual Paulista \\ (UNESP), São Paulo, SP \\ ${ }^{*}$ Associação Educacional Dom Bosco (AEDB), Resende, RJ \\ ** Faculdade de Engenharia do Campus de Guaratinguetá (FEG) - Universidade Estadual Paulista
}

(UNESP), São Paulo, SP

\begin{abstract}
Resumo: A venda de produtos eletroeletrônicos cresce em função das inovações tecnológicas e da rapidez com que eles se tornam obsoletos, refletindo no aumento de um resíduo descartado denominado Resíduos de Equipamentos Eletroeletrônicos (REEE) ou Lixo Eletrônico. Oriundo do descarte de eletroeletrônicos, tais como desktops, notebooks, impressoras e celulares, o REEE é um problema relevante, pois contém substâncias danosas ao meio ambiente e à saúde humana. Dessa forma, tornase necessário uma disposição final adequada. Com a criação da Política Nacional de Resíduos Sólidos (PNRS) no Brasil, os fabricantes, importadores, distribuidores e comerciantes de produtos eletroeletrônicos devem estruturar e implementar sistemas de Logística Reversa (LR) mediante retorno dos produtos após o uso pelo consumidor. Apesar de muitas empresas do setor de eletroeletrônicos se preocuparem com a LR de seus produtos, a revisão da literatura indica poucos resultados, evidenciando carência de trabalhos sobre o tema. $O$ artigo analisa o panorama da LR e sua inter-relação com o lixo eletrônico e a tecnologia de identificação de produtos, com propósito de contribuir com a prática da PNRS. Para tanto, foi realizada uma revisão sistemática da literatura envolvendo a Logística Reversa, o Lixo Eletrônico e as Tecnologias de Identificação de Produtos. Por meio de um estudo de caso, Projeto SmartWaste da Hewlett-Packard (HP), pode-se inferir que o Código de Barras e a Identificação por Rádio Frequência (RFID) são tecnologias úteis e viáveis nas práticas de LR para o lixo eletrônico.
\end{abstract}

Palavras-chave: Logística Reversa. Lixo Eletrônico. Código de Barras. Identificação por Rádio Frequência. Revisão Sistemática da Literatura. Estudo de Caso.

Abstract: The electrical and electronic products sales grow in close connection to technological
innovations and the speed in which they become obsolete, reflecting in the increase of a discarded
residue called Waste Electrical and Electronic Equipment (WEEE) or E-waste. From the disposal of
electronics devices such as desktops, notebooks, printers and cell phones, e-waste is a major problem
because it contains many substances harmful to the environment and to human health. Thus, it becomes
necessary to a proper disposal. With the creation of the National Policy on Solid Waste (PNRS) in Brazil,
manufacturers, importers, distributors and retailers of electrical and electronic products and their
components must structure and implement reverse logistics systems (LR) upon return of the products
after use by the consumer. Although many companies in the consumer electronics industry worry about
the LR of its products, the literature review indicates few results, showing lack of work on the topic. The
article analyzes the panorama of LR and its interrelation with e-waste and identification technology
products, with the purpose of contributing to the practice of PNRS. To this end, a systematic review of
literature, involving Reverse Logistics, E-waste and product identification technologies was held. By a

Revista Produção Online, Florianópolis, SC, v. 16, n. 2, p. 633-677, abr./jun. 2016. 
case study, SmartWaste Project from Hewlett-Packard (HP), it can be inferred that the Barcode and Radio Frequency Identification (RFID) technologies are useful and viable to improve the RL practices applied to e-waste.

Keywords: Reverse Logistics. E-waste. Bar code. Radio Frequency Identification. Systematic Review of Literature. Case Study.

\section{CONTEXTUALIZAÇÃo}

Um estudo realizado pela United Nations University - Institute for the Advanced Study of Sustainability (UNU-IAS) revelou que o Brasil é o oitavo maior produtor de lixo eletrônico do mundo, com mais de 1,1 milhão de toneladas geradas em 2014 (BALDÉ et al., 2014). Atualmente, no Brasil, há mais de 1,5 milhão de toneladas de lixo eletrônico sem tratamento para recuperação de seus componentes (PSP, 2014). O potencial do impacto ambiental e de saúde pública desse tipo de resíduo é um dos principais fatores a serem observados para a definição de ações preventivas a serem adotadas pela sociedade.

Os problemas ambientais, no mundo, não são novos. Andrade, Tachizawa e Carvalho (2002) relatam que a industrialização provocou profundos impactos no meio ambiente, tanto físicos quanto econômicos e sociais. Nesse contexto, vale observar que os seres humanos constituem o centro das preocupações relacionadas ao desenvolvimento sustentável, tendo direito a uma vida saudável, em harmonia com o meio ambiente. (MARCHESAN; STEIGLEDER; CAPELLI, 2008).

Define-se desenvolvimento sustentável como aquele que atende às necessidades do presente sem comprometer a possibilidade de as gerações futuras satisfazerem suas próprias necessidades. Nessa perspectiva, a proteção ambiental deve ser parte integrante do processo de tomada de decisão estratégica.

O desenvolvimento sustentável vem, gradativamente, ganhando corpo e expressão política, o que são frutos da percepção de uma crise ambiental global (NASCIMENTO, 2012). Pereira et al. (2013) explicam que fatos relevantes ocorridos nas últimas décadas, como a Conferência de Estocolmo (1970), Our Common Future (1980), Eco 92 (1990) e Rio+10 (2000), evidenciam uma preocupação com questões ambientais. De fato, a mitigação dos impactos ambientais tem ocupado a agenda gerencial do desenvolvimento sustentável (XAVIER; CORRÊA, 2013), sobretudo em relação ao equilíbrio das dimensões econômicas, sociais e ambientais - Triple Bottom 
Line (NIKOLAOU; EVANGELINOS; ALLAN, 2013; SARTORI; LATRÔNICO; CAMPOS, 2014).

Pode-se definir Logística Reversa (LR) como um instrumento de desenvolvimento econômico e social caracterizado por um conjunto de procedimentos destinados a viabilizar a restituição dos resíduos sólidos ao setor empresarial, seja para reaproveitamento, seja para outra destinação final ambientalmente adequada (BRASIL, 2010). A LR pode contribuir para o desenvolvimento sustentável, visto que ela busca viabilizar a coleta e a restituição dos resíduos ao setor empresarial, para reaproveitamento em seu ciclo ou em outros ciclos produtivos. Esse instrumento ajuda a reduzir ou eliminar resíduos por meio da reciclagem, do reúso e da compostagem (MIGUEZ, 2012); e, com seus benefícios ambientais, econômicos e sociais, a LR é indicada como um diferencial competitivo no processo de desenvolvimento de produtos e na tomada de decisões estratégicas das empresas e do governo.

Atualmente, há ações das empresas e do governo brasileiro para amenizar os efeitos dos impactos no meio ambiente. Tem-se, na Lei 12.305, de 02 de agosto de 2010, que instituiu a Política Nacional de Resíduos Sólidos (PNRS), a determinação de que fabricantes, importadores, distribuidores e comerciantes de produtos eletroeletrônicos (como refrigeradores, televisores, notebooks, desktops, impressoras e celulares) devem implementar sistemas de LR, que preveja retorno dos produtos após o uso pelo consumidor.

A PNRS está ancorada na ideia de responsabilidade compartilhada sobre 0 resíduo que produziu e/ou consumiu, além de exigir do fabricante uma análise do ciclo de vida do produto e de sua produção. Considerada um dos instrumentos mais desafiadores trazidos pela PNRS, a LR representa um desafio para sociedade e governo brasileiros que se propõem a implantá-la, viabilizando a responsabilidade compartilhada pelo ciclo de vida dos produtos. Com a PNRS, o crescimento ambientalmente sustentável será obrigatório para aqueles que se envolverem com a produção.

Apesar das determinações da PNRS, Ferreira e Vicente (2011) alertam sobre a complexidade de se estruturar um processo eficiente de LR dos resíduos sólidos. Essa complexidade apresenta uma relevância especial no caso do setor de eletroeletrônicos, pois seus resíduos crescem rapidamente em razão da obsolescência 
de seus produtos. Há de expectativa que as tecnologias de identificação de produtos auxiliam na implementação de sistemas de LR e na destinação adequada dos resíduos sólidos.

Nesse contexto, o presente trabalho preocupa-se com a sustentabilidade ambiental, a correta destinação dos resíduos sólidos e a relação entre a LR e a PNRS. Seus objetivos são esclarecer a situação do setor de eletroeletrônicos e de seus resíduos no Brasil, e explicar o funcionamento e os benefícios dos processos de rastreabilidade advindos dos sistemas de $\mathrm{LR}$, os quais operam por meio de tecnologias de identificação de produtos, como o Código de Barras, a Etiqueta Inteligente e a Identificação por Rádiofrequência - RFID (Radio Frequency Identification).

$\mathrm{O}$ artigo busca oferecer um panorama útil aos pesquisadores desse tema, o qual, cada vez mais, vem atraindo a atenção e demandado novas regulamentações. Ele está organizado como se segue. Na próxima seção, estão descritos os procedimentos metodológicos utilizados; na Seção 3, descreve-se a situação em que se encontram o setor de eletroeletrônicos, os Resíduos de Equipamentos Eletroeletrônicos (REEE) e a Logística Reversa (LR); na seção seguinte, apresentamse os conceitos e aplicações das tecnologias de identificação de produtos; na Seção 5, há uma comparação entre as tecnologias de identificação de produtos; na Seção 6, apresenta-se e discute-se um estudo de caso do Projeto SmartWaste da HewlettPackard (HP); finalmente, na última seção, estão as considerações finais do trabalho, seguidas das referências.

\section{REVISÃO SISTEMÁTICA DA LITERATURA}

A Revisão Sistemática da Literatura (RSL) foi realizada com artigos publicados no período de 2002 a 2014 e que foram encontrados na plataforma Web of Science e em outras bases de dados nacionais e internacionais, com as palavras-chave: $e$ waste, reverse logistics e RFID.

Figura 1 - Perfil das Publicações com palavras-chave: RFID

(1a) Artigos publicados por ano

(1b) Citações por ano 

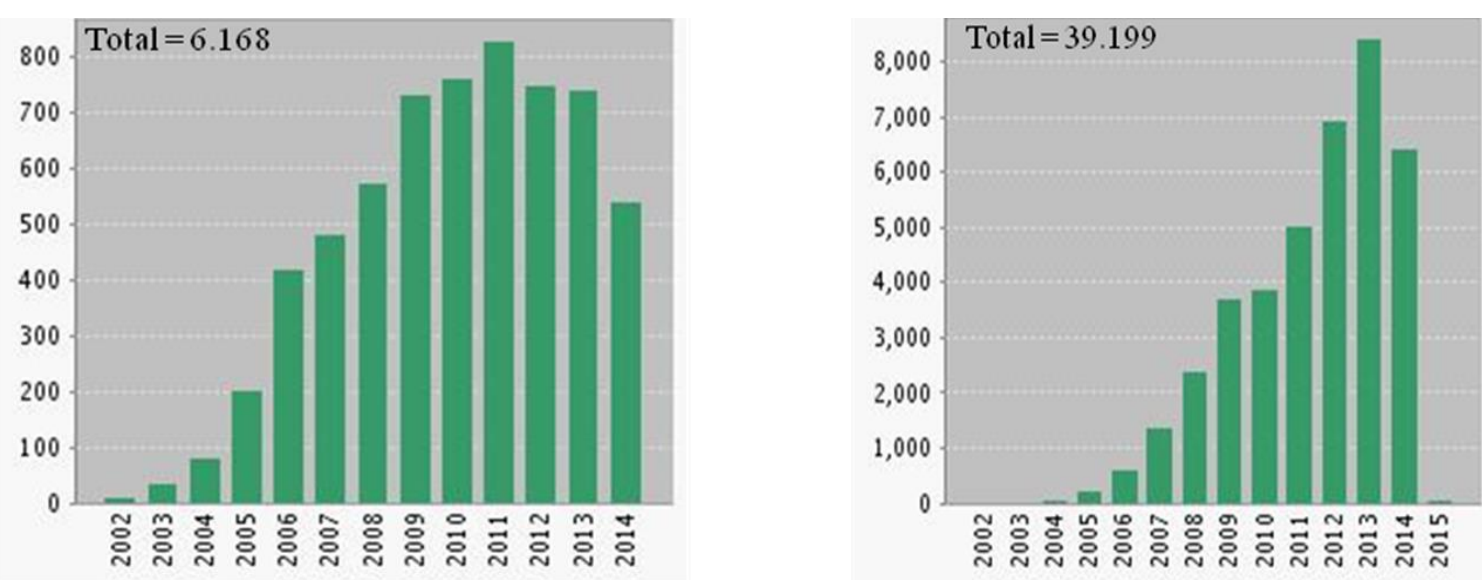

Fonte: Web of Science

A busca usou o campo topic, que registra título, resumo, palavras-chave e keywords plus. O tipo de texto analisado foi Article/Review, e consideraram-se publicações doa anos de 2002 a 2014. Nas Figuras (1a), (1b), (2a), (2b), (3a) e (3b), apresentam-se evidências de que houve um crescente interesse pelos temas RFID, Logística Reversa e Lixo Eletrônico, e as Figuras (4a) e (4b) revelam carência de estudos sobre a Logística Reversa do Lixo Eletrônico.

Figura 2 - Perfil das Publicações com palavras-chave: Reverse Logistics

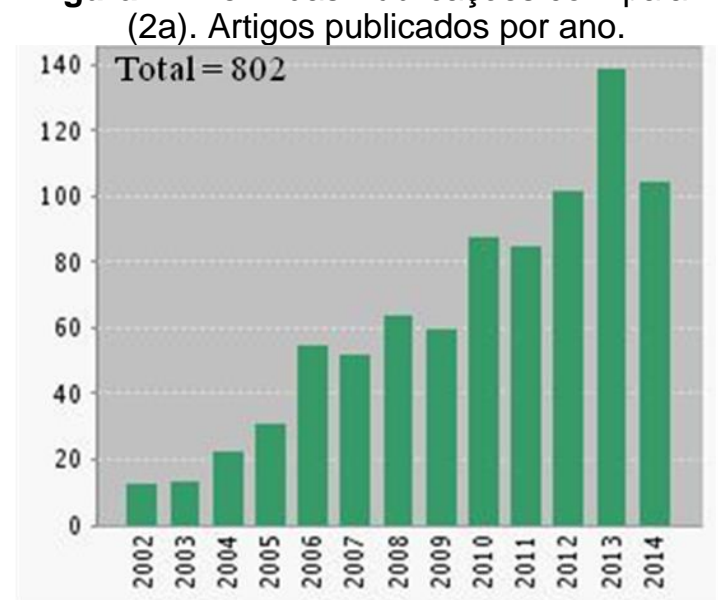

(2b). Citações por ano.

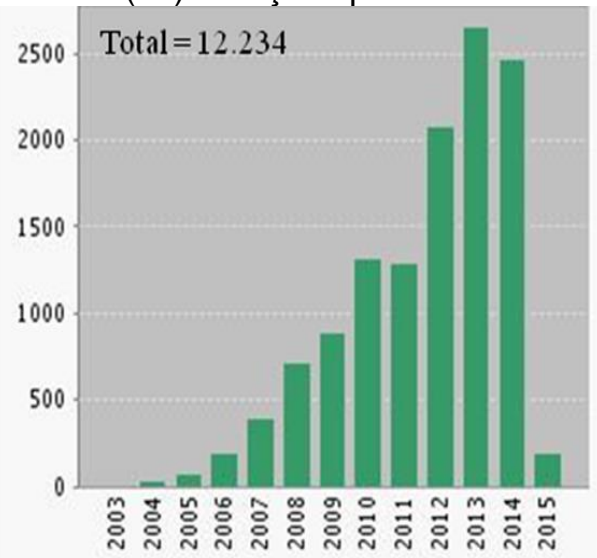

Fonte: Web of Science 
Figura 3 - Perfil das Publicações com palavras-chave: E-waste
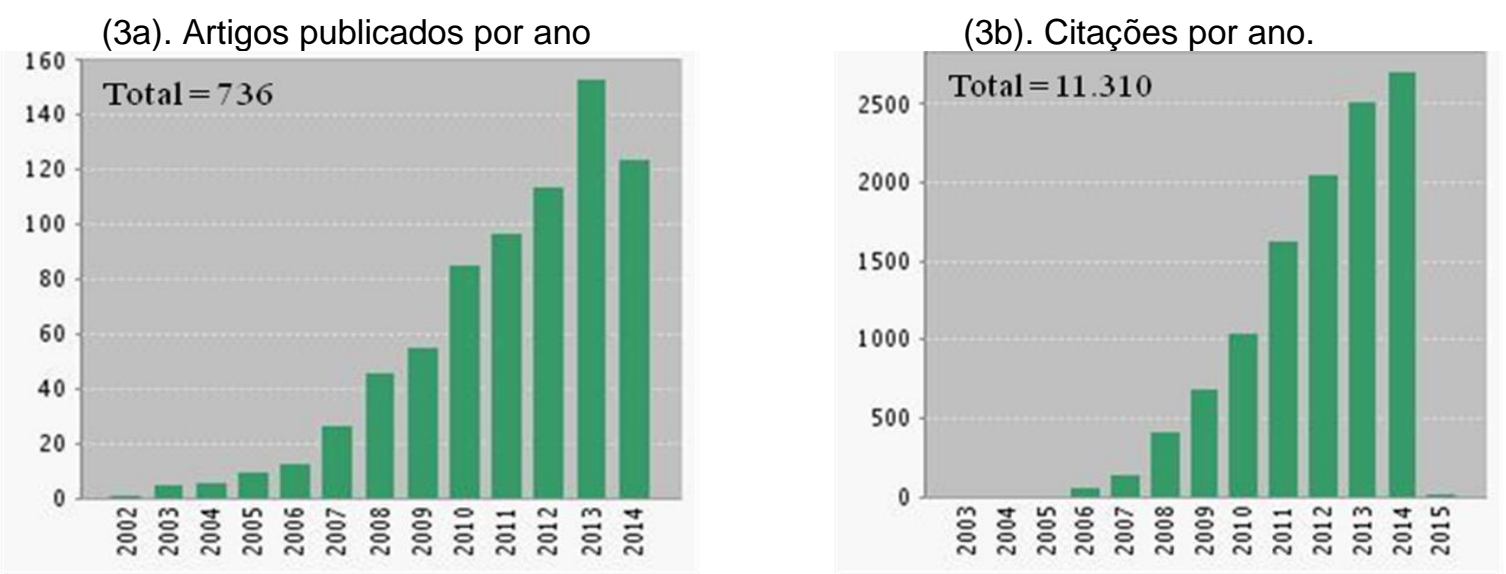

Fonte: Web of Science

Ao pesquisar conjuntamente as palavras-chave RFID, Reverse Logistics e Ewaste, não foram encontrados registros. Esse resultado indica oportunidades de ampliar aspectos teóricos sobre LR do lixo eletrônico. Ademais, na base Scientific Eletronic Library Online (SciELO), não há referências sobre o tema LR do lixo eletrônico entre os anos de 1999 e 2012 (ARAÚJO et al., 2013).

Figura 4 - Perfil das Publicações com palavras-chave: Reverse Logistics and E-waste (4a). Artigos publicados por ano

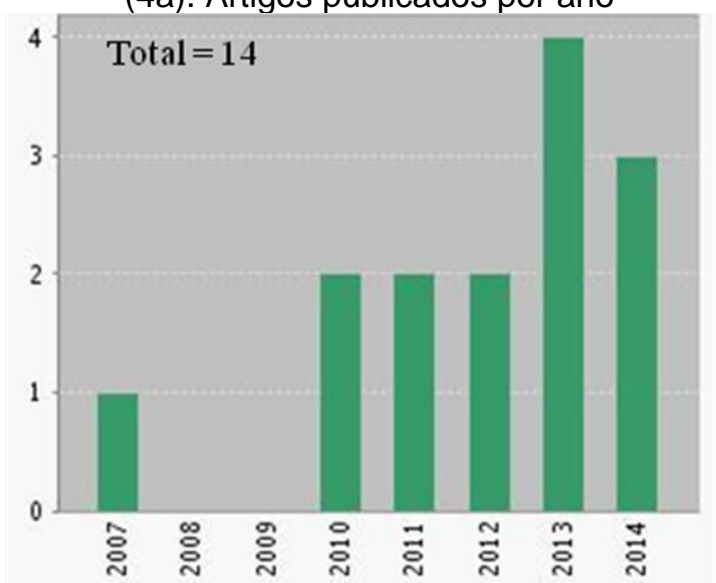

(4b) Citações por ano

Fonte: Web of Science.

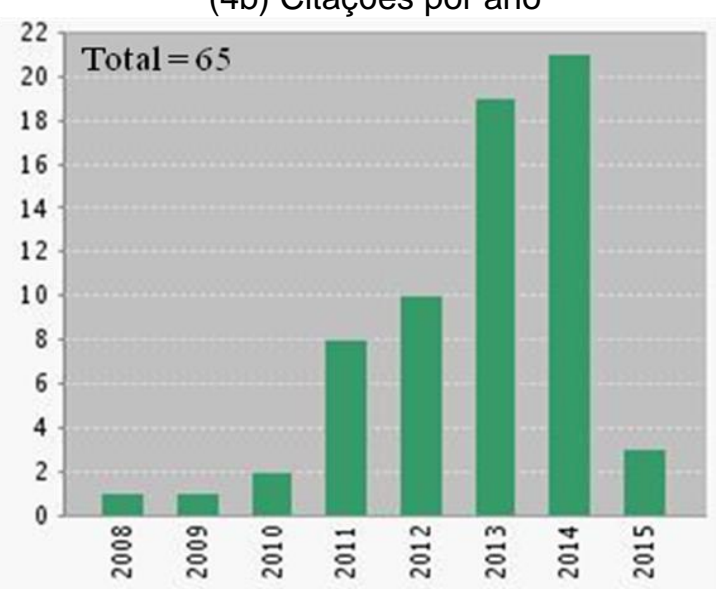

\section{SETOR DE ELETROELETRÔNICOS E LIXO ELETRÔNICO}

O Setor de Eletroeletrônicos reúne 4 mil empresas, representa 3,3\% do PIB brasileiro e engloba quantidade e variedade muito grandes de produtos, que podem ser agrupados em conjuntos denominados linhas, sendo definidas cores para cada 
agrupamento (PSP, 2014): Linhas Branca, Marrom, Azul e Verde. A Figura 5 apresenta esses agrupamentos, os principais produtos que os compõem, bem como outras características relevantes.

Figura 5 - Agrupamentos de produtos eletroeletrônicos
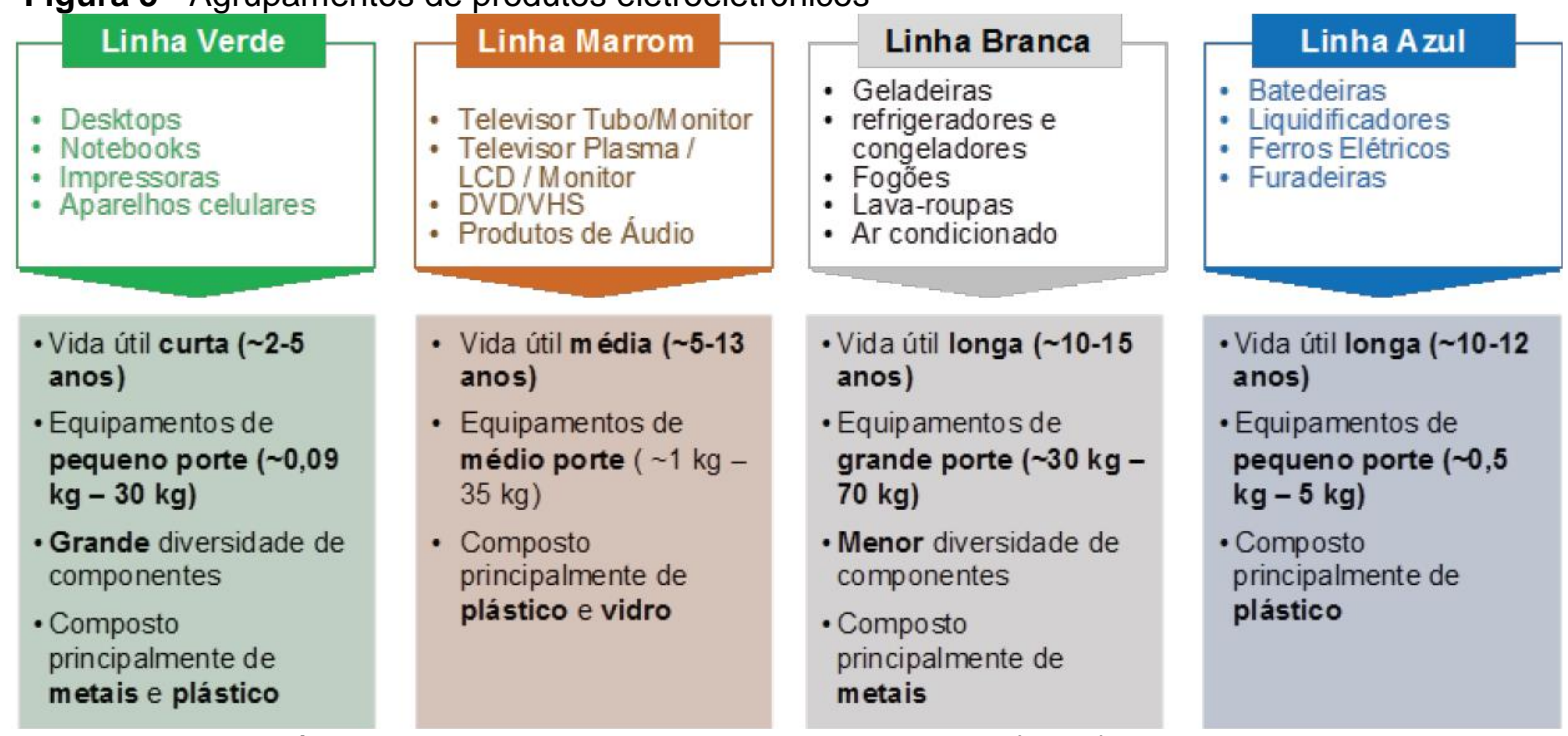

Fonte: ABDI - Agência Brasileira de Desenvolvimento Industrial (2013)

Para a gestão desses produtos, o setor privado está organizado em duas entidades específicas: a Associação Brasileira da Indústria Elétrica e Eletrônica (ABINEE), que representa a Linha Verde, e a Associação Nacional de Fabricantes de Produtos Eletrônicos (ELETROS), que representa as linhas Marrom, Branca e Azul.

Cresce a cada ano o percentual eletrônico presente nos produtos finais e em toda a cadeia produtiva do país. Dados divulgados pela ABINEE (2012) mostram que, entre 2003 e 2010, o setor obteve um crescimento de 110\% no faturamento. Ou seja, ele mais que dobrou suas vendas nesse período. A produção de celulares, por exemplo, cresceu 125\% em sete anos (de 2003 a 2010), passando de 27 milhões para 61 milhões de unidades anuais. São mais de 240 milhões de aparelhos para 191 milhões de brasileiros, o que quer dizer que há mais celulares em uso do que residentes no país. Em 10 anos, o Brasil pode alcançar a segunda posição na compra desses aparelhos em termos mundiais.

Em ritmo ainda mais elevado, seguiu a produção de computadores. De 2003 a 2010, a produção anual desses equipamentos aumentou 337\%, passando de 3,2 milhões para 14 milhões de unidades ao ano. Em 2010, o Brasil movimentou 4,5 
bilhões de dólares no mercado de computadores portáteis, ocupando o quinto lugar no ranking mundial.

Por outro lado, o ciclo de vida dos produtos eletroeletrônicos está cada vez mais curto em razão das constantes inovações tecnológicas. Como consequência, a descartabilidade desses produtos cresce (LEITE, 2009), trazendo preocupações sobre sua gestão e reciclagem (PANT, 2013). Ao fim de sua vida útil, esses produtos passam a ser considerados REEE ou Lixo Eletrônico.

Anualmente, entre 20 e 50 milhões de toneladas de lixo eletrônico são gerados no mundo (OLIVEIRA; EL-DEIR, 2011; TRIGO; BALTER, 2013). O Brasil é o oitavo maior produtor de lixo eletrônico do mundo, com mais de 1,1 milhão de toneladas geradas em 2014. Os Estados Unidos estão em primeiro lugar, com 7,072 milhões de toneladas geradas, China em segundo, com 6,033 milhões, Japão em terceiro, com 2,2 milhões, Alemanha em quarto, com 1,769 milhões, Índia em quinto, com 1,641 milhões, Reino Unido em sexto, com 1,511 milhões, e França em sétimo, com 1,419 milhões de toneladas geradas em 2014. A geração per capita de REEE no Brasil é estimada em $7,0 \mathrm{~kg} / \mathrm{hab} / \mathrm{ano}$, o que o coloca na $78^{\circ}$ posição entre os 183 países analisados pela UNU-IAS (BALDÉ et al., 2014). Estima-se que, no Brasil, foi gerado 1.100,66 milhar de toneladas de REEE em 2014, podendo chegar a 1.376,13 em 2016 (Figura 6).

Figura 6 - Geração de REEE no Brasil - 2011 a 2020

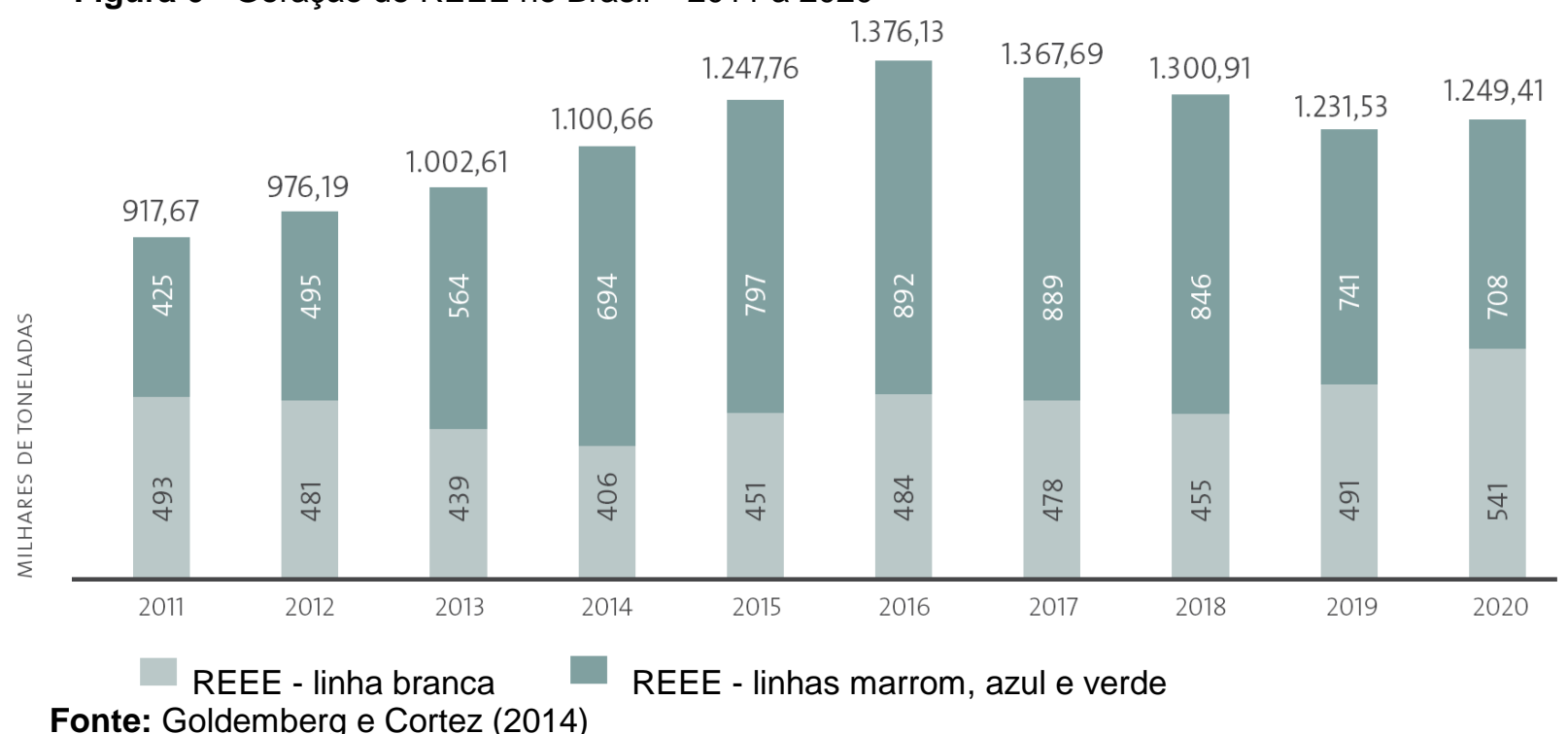

Revista Produção Online, Florianópolis, SC, v. 16, n. 2, p. 633-677, abr./jun. 2016. 
Ademais, estima-se que há mais de 1,5 milhão de toneladas de REEE no Brasil sem tratamento para recuperação de seus componentes (PSP, 2014). Além das questões de cunho estatístico, outro aspecto que merece atenção são as características dos REEE. Quintanilha (2009), Natume e Sant'anna (2011) e Martins et al. (2011) alertam que os REEE possuem substâncias nocivas à saúde e ao meio ambiente. Eles são compostos por plásticos, vidros e metais pesados tóxicos e geram dois tipos de riscos:

a) Contaminação dos consumidores que utilizam equipamentos obsoletos e das pessoas envolvidas com a coleta, triagem e reciclagem dos REEE;

b) Contaminação do meio ambiente, pois, mesmo em aterros, o contato dos metais pesados com a água contamina o chorume. Penetrando no solo, esses metais podem contaminar lençóis subterrâneos.

O Quadro 1 apresenta elementos presentes nos REEE e os principais danos que podem causar à saúde humana. Alguns desses REEE ainda recebem jatos de substâncias químicas para protegê-los da corrosão ou para retardar chamas. Como a extração de cada elemento químico exige um procedimento diferenciado, sua separação para processamento e reciclagem apresenta uma complexidade, um custo e um impacto muito maiores do que o tratamento de resíduos das latas de alumínio e garrafas de vidro (ABDI, 2013). Destaca-se que o Brasil tem enfrentado crescentes problemas de saúde e danos ambientais com a reciclagem informal dos REEE (SCHLUEP, 2009).

Quadro 1 - Principais males do lixo eletrônico

\begin{tabular}{|c|l|}
\hline Metal & \multicolumn{1}{|c|}{ Principais danos à saúde humana } \\
\hline Alumínio & Mal de Alzheimer. \\
\hline Bário & Elevação da pressão arterial e efeitos no sistema nervoso central. \\
\hline Cádmio & Descalcificação óssea, lesão renal, enfisema pulmonar, deformação fetal e câncer. \\
\hline Chumbo & Alterações gastrintestinais, neuromusculares e hematológicas. \\
\hline Cobre & Lesões no fígado. \\
\hline Cromo & Anemia, alterações hepáticas e renais, câncer do pulmão. \\
\hline Mercúrio & Lesões cerebrais e envenenamento no sistema nervoso central. \\
\hline Níquel & Câncer. \\
\hline Prata & Letal ao homem. \\
\hline
\end{tabular}

Fonte: adaptado de ABDI - Agência Brasileira de Desenvolvimento Industrial (2013)

Diante desse cenário, o problema da destinação dos REEE tem preocupado estudiosos ligados ao tema do desenvolvimento sustentável na esfera internacional 
(SEO; FINGERMAN, 2011). O tema vem ganhando espaço nas discussões (LAVEZ; SOUZA; LEITE, 2011) e tem levado a sociedade a pressionar empresas e governos para o seu equacionamento. Como resultado disso, principalmente nos países em desenvolvimento - devido ao avanço tecnológico, ao aumento da produção e às opções para destinação final dos REEE (PANT, 2013), há um interesse na aplicação da LR (ARAÚJO et al., 2013). De fato, regiões como Alemanha, Estados Unidos, Japão, Escandinávia, Reino Unido e União Europeia em geral (no total, 27 países) têm desenvolvido uma série de normas sobre LR de REEE para adequarem o crescimento econômico às questões ambientais (LEITE, 2009; PEREIRA et al., 2013).

O Brasil, por sua vez, vem apresentando relevante atuação política, de forma a contribuir para a gestão dos resíduos sólidos. A PNRS é um exemplo nesse sentido e representa um marco regulatório da exigência desafiadora da implementação de sistemas de LR por parte do setor de eletroeletrônicos. No entanto, ainda há várias deficiências quanto ao gerenciamento ambiental dos REEE no Brasil (PSP, 2014): i) ainda não há sistemas de LR implantados e ofertados aos consumidores; ii) quanto à destinação, não existem dados consolidados do setor; iii) não há estimativa de custos para a coleta e reciclagem dos REEE; iv) as iniciativas para recolha dos REEE ainda são incipientes e inadequadas, considerando a forma como estão estruturadas e ofertadas; e v) há carência de normas sobre descarte e recuperação dos REEE.

Independentemente dessas dificuldades, o setor de eletroeletrônicos terá que se

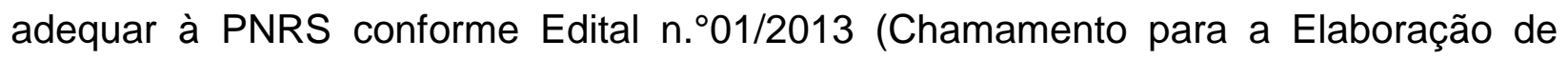
Acordo Setorial para a Implantação de Sistema de LR), que estabelece metas para o ano de 2021 (GOLDEMBERG; CORTEZ, 2014):

- A LR deverá ser estruturada e implantada nos municípios com população superior a 80 mil habitantes;

- Deverá haver ao menos um ponto de coleta para cada 25 mil habitantes nos municípios com LR implantada;

- Pelo menos $17 \%$, em peso, dos REEE, em relação à quantidade de produtos colocados no mercado, deverão ser coletados e destinados de forma ambientalmente adequada.

Há oportunidades de se ampliarem estudos sobre a LR dos REEE e de se indicarem elementos para seu gerenciamento eficaz de longo prazo. Nesse contexto, 
compreende-se a tecnologia de identificação de produtos, descrita na próxima seção, como um instrumento para se promover a restituição do lixo eletrônico ao setor empresarial, possibilitando seu reaproveitamento ou outra destinação adequada.

\section{TECNOLOGIA DE IDENTIFICAÇÃO DE PRODUTOS}

As tecnologias de identificação de produtos são uma realidade, sendo que a do código de barras é a mais usada; e há, também, a RFID - Radio Frequency Identification, que está presente em muitas áreas, com uma quota de mercado crescente. Para Xavier e Corrêa (2013), essas tecnologias facilitam e automatizam a identificação de itens, de modo que são úteis na gestão de redes de suprimento direta e reversa para o rastreamento de itens.

A rastreabilidade é um processo que possibilita a identificação do produto no sistema da LR por meio da coleta e armazenagem de suas informações. Os sistemas de rastreabilidade e Tecnologia da Informação (TI) devem estar relacionados, uma vez que a gestão da informação pode tornar os processos mais precisos por meio do uso de recursos informatizados.

\subsection{Tecnologia de Códigos de Barras}

Os códigos de barras podem ser unidimensionais ou bidimensionais e permitem a identificação de produtos por intermédio da representação gráfica de dados e da leitura ótica com aparelhos a laser, chamados scanners ou leitoras. O código de barras e a leitora foram patenteados em 1952 por Joseph Woodland e Bernard Silver, mas somente em 1974 é que se deu início à sua aplicação (REI, 2010).

Os unidimensionais são representados por uma sequência de números (ou alfanuméricas) e por linhas verticais de várias larguras, com espaços entre elas. Já os bidimensionais são representados por pontos, quadrados, hexágonos e outras formas, o que permite que mais informações sejam representadas em menor espaço.

Segundo Hayat (2013), um código de barras unidimensional pode produzir 10.000 bilhões de códigos únicos, enquanto o bidimensional pode gerar cerca de 100 
vezes mais informação. O Quadro 2 apresenta os tipos de códigos de barras e a descrição de cada um deles.

Em geral, a tecnologia de códigos de barras reduz o erro na entrada de dados e o tempo de processamento, bem como aumenta a rastreabilidade. Com todas as suas vantagens, essa tecnologia tornou-se uma solução generalizada para a gestão da cadeia de abastecimento (HAYAT, 2013), sendo largamente utilizada para identificar ativos fixos e retornáveis, documentos, contêineres, cargas, serviços, entre outros.

Os códigos de barras podem ser impressos no produto ou fixados por meio de etiquetas. A Figura 7 mostra o processo de leitura ótica de um código de barras. Sequeira (2010) explica que a decodificação dos dados é realizada por meio de um scanner que emite um feixe de luz vermelho, o qual percorre todas as barras. No local da etiqueta em que a barra é escura, a luz é absorvida, e, no local onde há espaços, ela é refletida novamente para o scanner. Os dados capturados pela leitura ótica são transmitidos para um computador, onde são tratados e convertidos em alfabeto romano ou numeração árabe.

Portanto, as etiquetas de código de barras e os scanners são os elementos que constituem a base do sistema, sendo necessário possuir um middleware que filtre os dados recolhidos e também servidores para armazenamento de dados. 
Quadro 2 - Tipos de Códigos de Barras

\begin{tabular}{|c|c|c|c|}
\hline \multirow{5}{*}{ 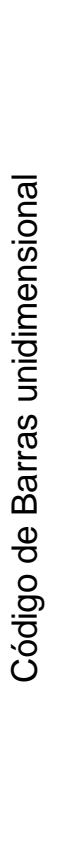 } & Tipo & Descrição & Figura representativa \\
\hline & EAN/UPC & $\begin{array}{l}\text { Código mais popular. Usado para leitura no Ponto De } \\
\text { Venda (PDV) devido à agilidade na captura da } \\
\text { informação. Permite codificar os GTIN-8, GTIN-12 e } \\
\text { GTIN-13. Formado por } 13 \text { dígitos: os três primeiros } \\
\text { representam o país, os quatro seguintes o código da } \\
\text { empresa filiada à EAN, os próximos cinco representam o } \\
\text { número de fabricação e o último é o dígito verificador. }\end{array}$ & $\begin{array}{cccc}7 & 1 & 1 & 1 \\
789 & 99999 & 1234 & 9 \\
\text { PAIS } & \text { EMPRESA PRODUTO } & \text { D.V. } \\
\end{array}$ \\
\hline & $\begin{array}{l}\text { GS1 } \\
\text { Databar }\end{array}$ & $\begin{array}{l}\text { Pode ser escaneado no PDV e ser muito menor que os } \\
\text { códigos EAN/UPC. Pode codificar informações adicionais } \\
\text { como número serial, de lote e/ou data de validade. }\end{array}$ & \\
\hline & GS1-128 & $\begin{array}{l}\text { Codifica todas as chaves GS1. Utilizado na } \\
\text { rastreabilidade por meio da codificação de informações } \\
\text { adicionais como número serial, número de lote, data de } \\
\text { validade, quantidades, número do pedido do cliente etc. } \\
\text { Não pode ser utilizado para identificar itens que passarão } \\
\text { pelo PDV. }\end{array}$ & \\
\hline & ITF-14 & $\begin{array}{l}\text { Codifica apenas GTINs, pode ser impresso diretamente } \\
\text { em substrato corrugado (caixa de papelão) oferecendo } \\
\text { um bom desempenho de leitura. Não pode ser utilizado } \\
\text { para identificar itens comerciais que passarão pelo PDV. }\end{array}$ & \\
\hline \multirow{4}{*}{ 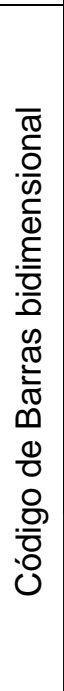 } & $\begin{array}{l}\text { GS1 } \\
\text { DataMatrix }\end{array}$ & $\begin{array}{l}\text { Codifica informações em espaços tão pequenos quanto } \\
\text { uma ampola de } 5 \mathrm{ml} \text {. Possui maior capacidade de } \\
\text { armazenamento de dados num espaço reduzido (de } 1 \text { a } \\
500 \text { caracteres), limitado à resolução da impressora. } \\
\text { Aplicação comum: marcação de itens pequenos como } \\
\text { circuitos integrados e impressos. }\end{array}$ & \\
\hline & $\begin{array}{l}\text { QR Code } \\
\text { (Quick } \\
\text { Response) }\end{array}$ & $\begin{array}{l}\text { Código matricial que visa leitura rápida, leitura por } \\
\text { câmeras CCD e tecnologia de processamento de } \\
\text { imagens. }\end{array}$ & \\
\hline & Aztec & $\begin{array}{l}\text { Facilidade de impressão e facilidade de decodificação. } \\
\text { Criado em } 1995 \text { por Andy Longacre, da Welch Allyn Inc. }\end{array}$ & \\
\hline & Maxicode & $\begin{array}{l}\text { Originalmente denominado código UPS (ou código 6). } \\
\text { Possui maior densidade em relação ao código Aztec, } \\
\text { porém requer impressora de mais alta resolução (térmica } \\
\text { ou a laser). }\end{array}$ & a@is \\
\hline
\end{tabular}

Fonte: adaptado de Conti (2011) e GS1 Brasil - Associação Brasileira de Automação (2014) 
Figura 7 - Processo de leitura de um código de barras

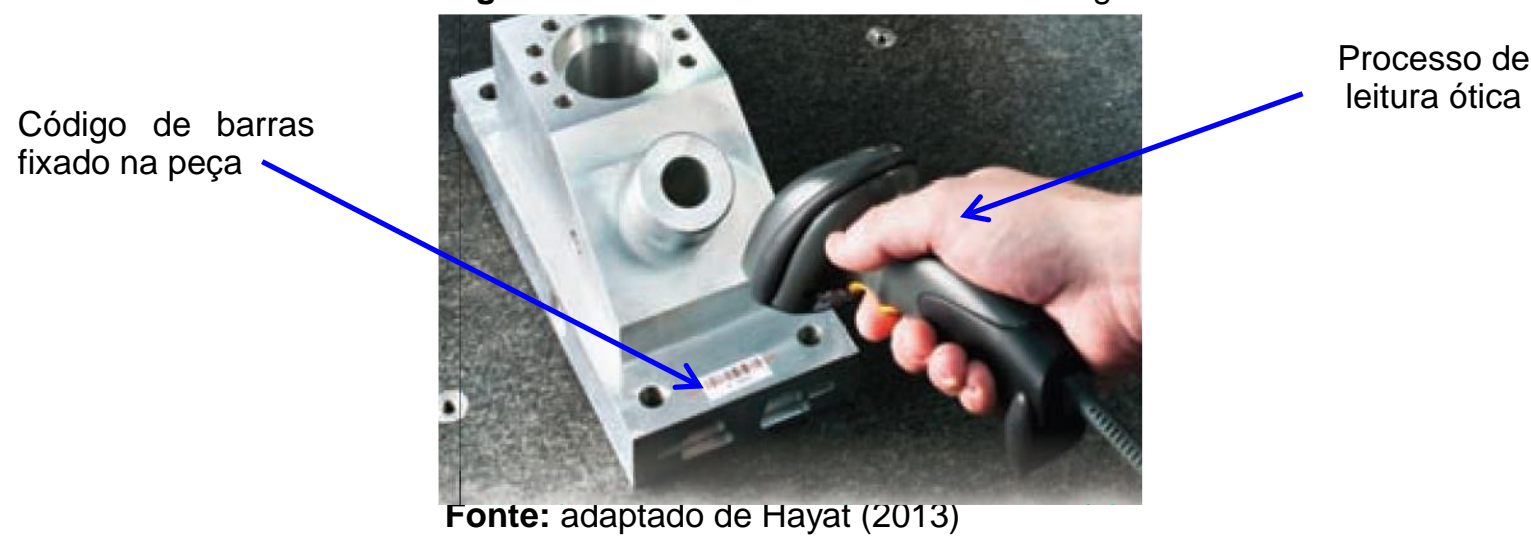

Apesar da sua vasta utilidade, a tecnologia de código de barras apresenta, de acordo com avaliações de vários autores, vantagens e desvantagens, como sintetizado no Quadro 3.

Com a evolução tecnológica, surgiu a possibilidade de introduzir, em etiquetas do tamanho das que trazem o código de barras, circuitos eletrônicos (microchips) capazes de acumular muito mais informações sobre um produto. Essa tecnologia envolve os conceitos de etiqueta inteligente (também chamada de tag, smart tag, transponder ou smart label) e de tecnologia RFID - Radio Frequency Identification (XAVIER e CORREA, 2013) e será descrita na sequência 
Quadro 3 - Vantagens e desvantagens do Código de Barras.

\begin{tabular}{|c|c|c|c|c|c|c|c|c|c|c|c|c|}
\hline & \multirow{2}{*}{ Descrição } & \multicolumn{11}{|c|}{ Autores } \\
\hline & & 1 & 2 & 3 & 4 & 5 & 6 & & 8 & 9 & 10 & $11 \mid 12$ \\
\hline \multirow{13}{*}{ 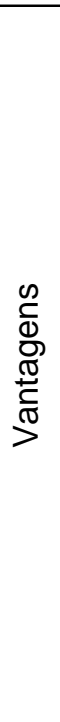 } & Existência de padrões a nível mundial. & & & & $\mathrm{x}$ & & & & & & & $\mathrm{x}$ \\
\hline & $\begin{array}{l}\text { Integra parceiros na gestão de redes de suprimento direta e } \\
\text { reversa. }\end{array}$ & & & & & & & & & $x$ & & \\
\hline & Tecnologia madura e disseminada no mercado global. & & & & $\mathrm{x}$ & $\mathrm{x}$ & & & & $\mathrm{x}$ & & \\
\hline & $\begin{array}{l}\begin{array}{l}\text { Permite adequar preceitos legais de responsabilidade } \\
\text { compartilhada. }\end{array} \\
\end{array}$ & & & & & & & & & $x$ & & \\
\hline & Estabilidade e segurança no processo de identificação. & & & & $\mathrm{x}$ & $\mathrm{x}$ & $\mathrm{x}$ & & & $\mathrm{x}$ & & \\
\hline & $\begin{array}{lccccc}\begin{array}{l}\text { Velocidade e exatidão no processo } \\
\text { disponibilização da informação. }\end{array} & \text { de leitura } & \text { e } \\
\end{array}$ & & & & & $x$ & $\mathrm{x}$ & & $\mathrm{x}$ & $x$ & & \\
\hline & Eficiência na rastreabilidade. & & & & & & & & $\mathrm{x}$ & $\mathrm{x}$ & & \\
\hline & $\begin{array}{lllll}\begin{array}{l}\text { Infraestrutura necessária } \\
\text { implementação. }\end{array} & \text { simples } & \text { e } & \text { facilidade } & \text { de } \\
\end{array}$ & & & & $\mathrm{x}$ & & & & & & & \\
\hline & Tecnologia de leitura simples e barata. & & & & $\mathrm{x}$ & $\mathrm{x}$ & & & & & & \\
\hline & Não exige formação especial aos operadores. & & & & $\mathrm{x}$ & & & & & & & \\
\hline & Baixo custo de implementação e manutenção. & & & & $\mathrm{x}$ & $\bar{x}$ & & & & & & \\
\hline & Reduz custos em relação à coleta manual de dados). & & & & & & $\mathrm{x}$ & & & & & \\
\hline & $\begin{array}{l}\text { Imune ao material que a etiqueta é colocada e a interferência } \\
\text { eletromagnética. }\end{array}$ & & & & $\mathrm{x}$ & & & & & & & \\
\hline \multirow{13}{*}{ 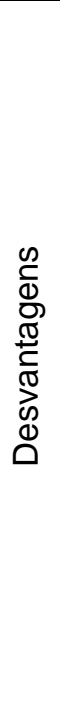 } & $\begin{array}{l}\text { O leitor deve ser direcionado fisicamente para possibilitar a } \\
\text { leitura do código (linha de visão). }\end{array}$ & $\mathrm{x}$ & $\mathrm{x}$ & $\mathrm{x}$ & $\mathrm{x}$ & $\mathrm{x}$ & $\mathrm{x}$ & $\mathrm{x}$ & & & $\mathrm{x}$ & $x$ \\
\hline & $\begin{array}{l}\text { Distância entre o leitor e o código a ser lido é muito pequena, } \\
\text { normalmente em centímetros. }\end{array}$ & & $\mathrm{x}$ & & $\mathrm{x}$ & & & & & & & \\
\hline & Não pode ser incorporada no objeto rastreado. & & & & & & & & & & & $\mathrm{x}$ \\
\hline & Operação manual (exige pessoas para capturar dados) & $\mathrm{x}$ & & & $\mathrm{x}$ & & & & & & & \\
\hline & Capacidade limitada de inserção de dados. & $\mathrm{x}$ & $\mathrm{x}$ & & $\mathrm{x}$ & $\mathrm{x}$ & $\mathrm{x}$ & $\mathrm{x}$ & & & & \\
\hline & Não permite alteração de dados inseridos nos códigos. & & $\mathrm{x}$ & & $\mathrm{x}$ & $\bar{x}$ & & & & & & \\
\hline & Leitura de um código por vez. & $\mathrm{x}$ & & & $\mathrm{x}$ & $\mathrm{x}$ & & $\mathrm{x}$ & & & & \\
\hline & Há risco de o código ser lido duas vezes. & $\mathrm{x}$ & & & & & & & & & & \\
\hline & $\begin{array}{l}\text { Códigos podem ser impressos incorretamente ou } \\
\text { danificados, o que dificulta ou impossibilita sua leitura. }\end{array}$ & $\mathrm{x}$ & & & & & $\mathrm{x}$ & & & & & \\
\hline & $\begin{array}{l}\text { Fragilidade das etiquetas e dificuldade de protegê-las, pois } \\
\text { pode prejudicar a leitura. }\end{array}$ & & $\mathrm{x}$ & & $\mathrm{x}$ & $\mathrm{x}$ & & & & & & \\
\hline & $\begin{array}{l}\text { Facilmente falsificável e a atos de vandalismo, pois não } \\
\text { possui mecanismo de segurança. }\end{array}$ & & & & $\mathrm{x}$ & & & & & & & \\
\hline & Luminosidade do ambiente pode afetar a leitura do código. & & & & $\mathrm{x}$ & & & & & & & \\
\hline & Sensível sobre a cor de fundo e ao material que é impresso. & & & & $\mathrm{x}$ & & & & & & & \\
\hline
\end{tabular}

Fonte: Adaptado de 1-Banzato (2005); 2-Bhuptani e Moradpour (2005); 3-Leite e outros (2008); 4-Rei (2010); 5-Sequeira (2010); 6-Conti (2010); 7-Ramanathan, Bentley e Ko (2012). 8-Hayat (2013); 9-Xavier e Corrêa (2013); 10-GS1 Brasil (2013); 11-Bachu, Saram e Kumas (2013); 12-GS1 Brasil (2014).

\subsection{Tecnologia RFID}

A RFID é uma tecnologia de identificação automática de produtos sem necessidade de fios, pois usa o campo eletromagnético de radiofrequência (RF) para transmitir dados entre uma etiqueta inteligente e uma leitora (HASHEMI; SARHADDI; HOSSEIN, 2013). Diferentemente da tecnologia de código de barras, a tecnologia RFID pode identificar centenas de itens etiquetados simultaneamente e não exige uma linha de visão entre a etiqueta inteligente e a leitora (LEITE et al., 2008). Dessa forma, Revista Produção Online, Florianópolis, SC, v. 16, n. 2, p. 633-677, abr./jun. 2016. 
a RFID acrescenta novas funcionalidades ao processo de leitura do código de barras (REI, 2010), superando suas limitações (BANZATO, 2005) e aumentando a eficiência dos serviços para as partes interessadas (AHSAN; SHAH; KINGSTON, 2010).

Assim, vê-se que um sistema de RFID desempenha um papel importante, no apoio à logística, devido ao seu potencial para identificar, rastrear e controlar as informações em toda a cadeia logística. A RFID proporciona aos fornecedores, fabricantes, distribuidores e varejistas informações precisas e em tempo real sobre os produtos.

Os conceitos e a tecnologia que permitiram a criação da RFID não são novos. Tudo começou em 1880, com a compreensão da energia eletromagnética, e depois em 1897, com a invenção do rádio. Na sequência, em 1922, foi desenvolvido o radar, e, em 1937, o Laboratório de Pesquisas Navais dos EUA (NRL) apresentou o Sistema IFF (Identification Friend-or-Foe), para identificar e distinguir aeronaves aliadas das inimigas. Em 1973, Mário W. Cardullo requisitou a primeira patente de um sistema ativo de RFID, e, no mesmo ano, Charles Walton recebeu a patente para um sistema passivo. A Figura 8 ilustra a evolução dessa tecnologia entre os anos de 1880 e 2003.

A RFID já provou o valor de sua utilização, continua a evoluir e proporciona várias aplicações nas empresas (AHSAS, 2011), tais como rastreamento e acompanhamento de objetos (aplicação mais comum), integração da cadeia de abastecimento (aplicação mais extensa do rastreamento), vigilância eletrônica de produtos, autenticação de documentos, controle de acessos, monitoramento de animais, pessoas e pacientes, detecção e monitoramento ambiental, pagamentos e automação industrial, entre outras aplicações (BHUPTANI; MORADPOUR, 2005). 
Figura 8 - Evolução da RFID

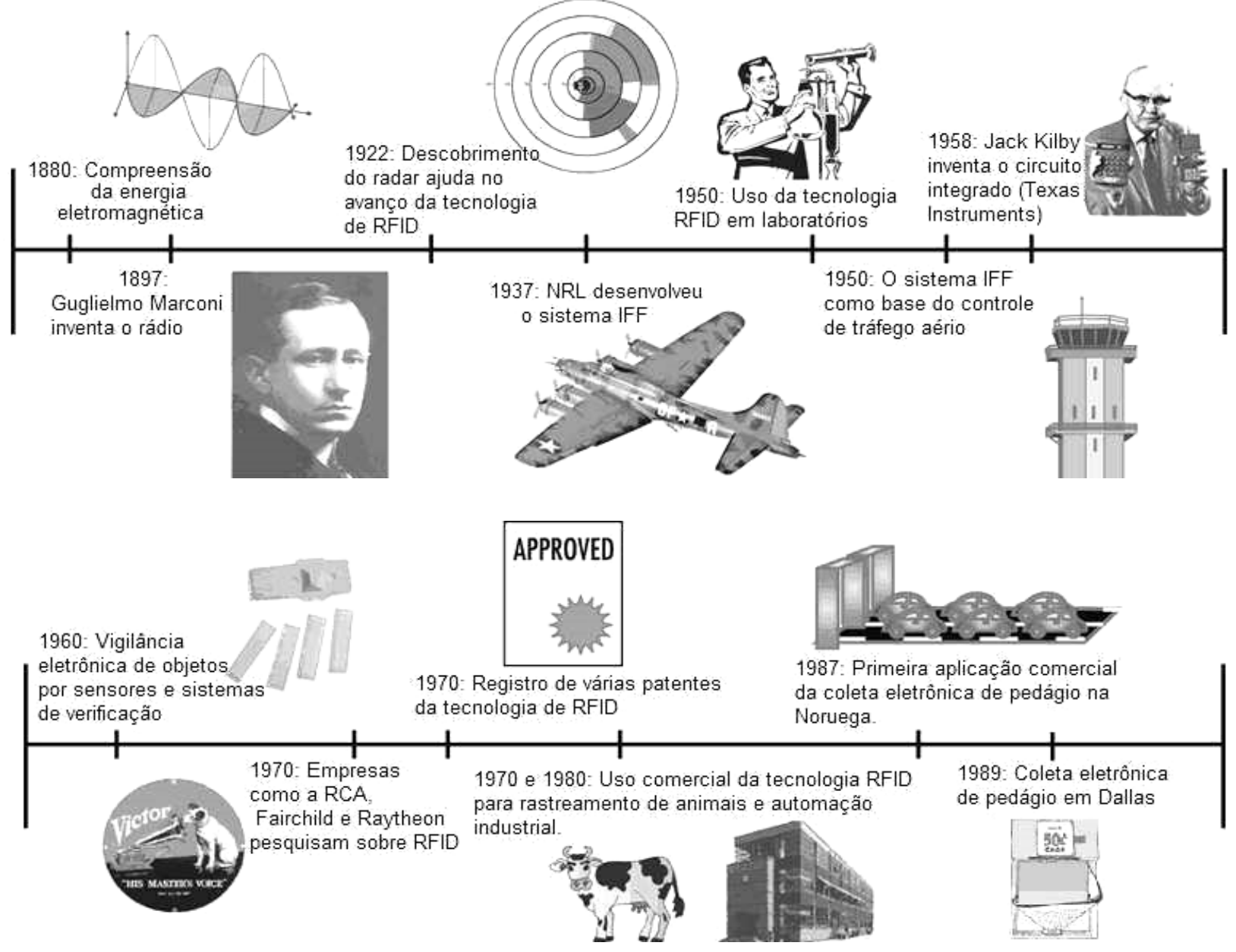

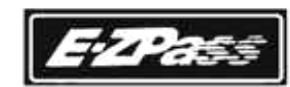

1990: A E-7 PASS

inicia um trabalho de padronização da

tecnologia RFID. ID
193
1950: Uso da tecnologia RFID em laboratórios tegrado (Texa struments)

1950. O sistema IFF como base do controle de tráfego aério

1970: Registro de várias patentes da tecnologia de RFID
1987: Primeira aplicação comercial da coleta eletrônica de pedágio na Noruega
1990: Surgimento de novas
aplicações para a tecnologia
RFID

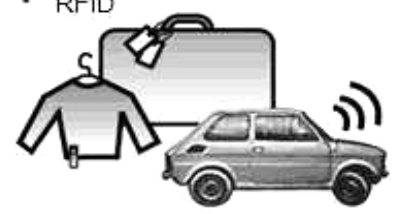

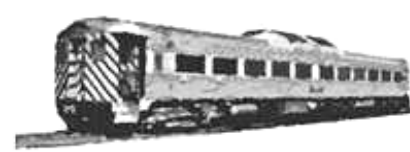

1990: Trens de ferro dos EUA equipados com RFID
1990: UHF Tags abrem novas possibilidades e soluções para a gerência da cadeia de suprimentos (uso em logística)

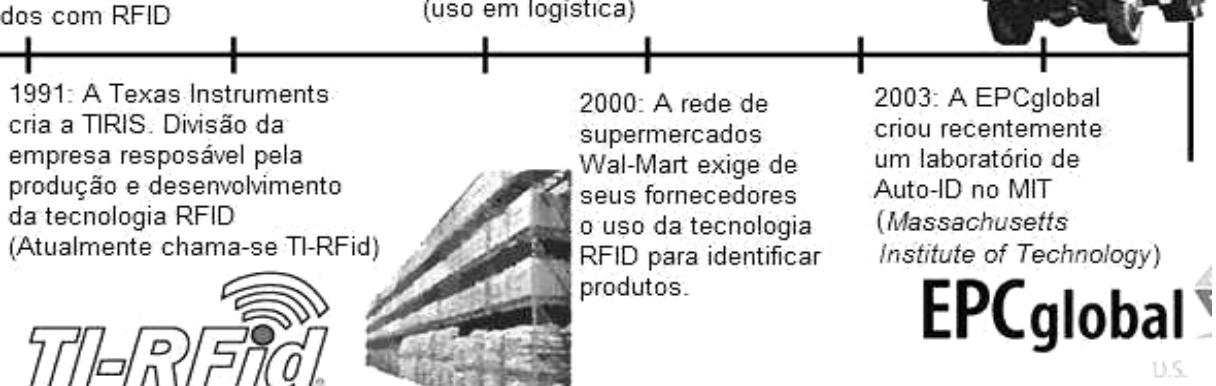

Fonte: Bhuptani e Moradpour (2005)

2003: Uso da tecnologia RFID pelo departamento de defesa dos EUA na operação de libertação do Iraque

Para o funcionamento de um sistema de RFID, os elementos básicos são: tag (etiqueta inteligente), antena, frequência de operação, leitor, RFID middleware e 
sistemas gerenciais. A tag, para a RFID, é um hardware que possui um microchip capaz de armazenar dados e uma antena que faz o papel de transmissor de dados entre a etiqueta e a leitora. A Figura 9 ilustra uma tag para a RFID.

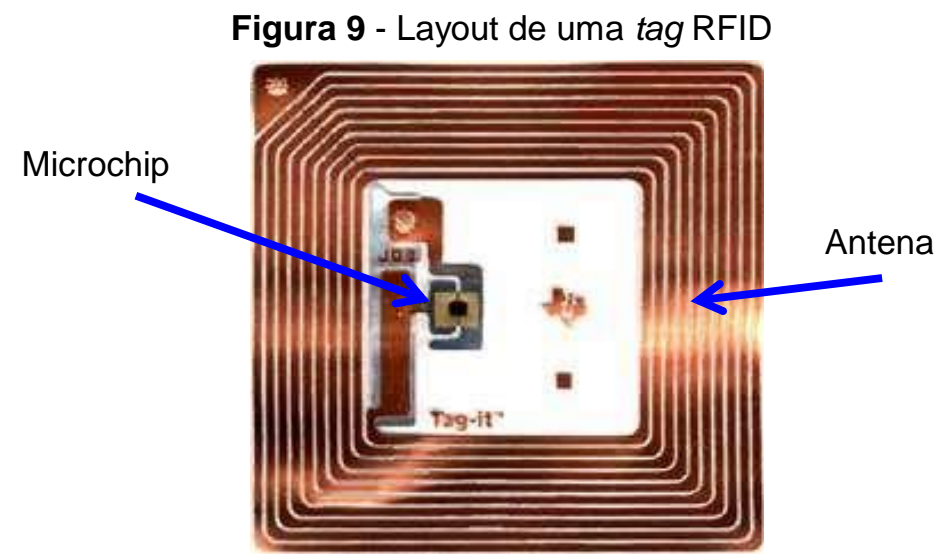

Fonte: Adaptado de Bachu, Saram e Kumas (2013)

Inicialmente, o Código Eletrônico do Produto (EPC) é gerado e gravado na tag RFID. O EPC é um número único, usado para identificar um item específico na cadeia de suprimentos. Ao se aproximar de uma leitora, a tag RFID, por meio de radiofrequência, envia automaticamente os dados do produto em que estiver embutida, tais como dimensão, paradeiro, número de identificação, histórico das temperaturas a que estava exposto, entre outras características estáticas e dinâmicas. Isso permite que a captura de dados dispense contato físico ou campo visual, o que é uma de suas maiores vantagens.

Assim, a RFID pode ser usada em ambientes com variações de temperatura e umidade, bem como em operações que envolvam grandes volumes de objetos (GS1 BRASIL, 2014). Tudo o que for identificado, no raio de ação da etiqueta, será registrado. Quanto maior a área de cobertura, maior será a "região ativa" entre as unidades operacionais, o que melhora a visão do fluxo de materiais entre as empresas (BATOCCHIO, 2011).

A seleção da tag depende da necessidade funcional de aplicação de um sistema de RFID. Dessa forma, existem atributos na etiqueta que alteram seu desempenho, como modelo, tipo e memória, conforme consta no Quadro 4. 
Quadro 4 - Atributos de uma tag RFID

\begin{tabular}{|c|c|}
\hline Atributo & Características \\
\hline Modelo & $\begin{array}{l}\text { Com microchip - a mais comum. Possui circuito integrado com memória para } \\
\text { realizar computações simples. } \\
\text { Sem microchip - baseia-se nas propriedades do material da tag para } \\
\text { transmissão de dados. Consegue alcances maiores de leitura e melhor } \\
\text { acurácia ao ler tags em líquidos e metais. Pode operar em temperaturas } \\
\text { extremas. É mais eficiente nas interferências de radiofrequência. Menor preço } \\
\text { por etiqueta. Não armazena dados novos e/ou adicionais. }\end{array}$ \\
\hline Tipo & $\begin{array}{l}\text { As tags RFID podem ser do tipo Passiva, Semi-passiva, Ativa ou Semi-ativa. } \\
\text { Cada uma delas usa distintas tecnologias com recursos diferentes. } \\
\text { Passiva - A mais simples e de maior aplicação. Não requer manutenção nem } \\
\text { bateria para operar. A energia vem do sinal transmitido pela antena e reflete de } \\
\text { volta a energia sobre a forma de ondas de rádio. Leve, baixo custo e vida útil } \\
\text { longa (até } 20 \text { anos). Mecanicamente mais flexível. Memória e capacidade } \\
\text { computacional muito limitadas. Alcance de até } 5 \text { metros. Menor acurácia. } \\
\text { Semi-passiva - Possui bateria com vida útil maior que } 5 \text { anos. A comunicação } \\
\text { com o leitor é idêntica ao das tags Passivas. Pode incorporar sensores que } \\
\text { registram qualquer condição que o sensor foi destinado a monitorar e até } \\
\text { mesmo a evolução de variáveis como temperatura, pressão, umidade, agentes } \\
\text { químicos, bactérias e até mesmo a detecção de adulterações a que o produto } \\
\text { está sujeito. Permite regravação de dados contidos na tag. Pode alimentar } \\
\text { circuitos com maiores funcionalidades. Alcance e acurácia maior que a tag } \\
\text { passiva. Maior custo que a tag passiva. } \\
\text { Ativa - Requer bateria para alimentar o microchip e para transmitir o sinal de } \\
\text { volta para o leitor RFID. Incorpora sensores e permite regravação de dados } \\
\text { contidos na tag. Oferece maior alcance, maior acurácia e maior memória que } \\
\text { as tags Passiva e Semi-passiva. Alto custo. Vida útil limitada imposta pela } \\
\text { bateria (entre } 5 \text { e } 10 \text { anos). } \\
\text { Semi-ativa - Requer bateria somente para operar o microchip. Oferece melhor } \\
\text { alcance e acurácia do que as tags Passiva e Semi-passiva a um custo menor } \\
\text { do que as tags ativas. }\end{array}$ \\
\hline Memória & $\begin{array}{l}\text { Somente leitura - os dados gravados apenas na hora da fabricação da etiqueta } \\
\text { tornam a etiqueta à prova de adulteração (característica das etiquetas sem } \\
\text { chips). } \\
\text { Uma gravação/várias leituras - A capacidade de gravar dados apenas uma vez } \\
\text { torna a etiqueta à prova de adulteração, mas é flexível a gravação dos dados } \\
\text { depois da fabricação da etiqueta. } \\
\text { Leitura/gravação - a que possui maior flexibilidade, porém a de maior } \\
\text { vulnerabilidade de adulteração e sobreposição de dados. }\end{array}$ \\
\hline
\end{tabular}

Fonte: Adaptado de Banzato (2005); Bhuptani e Moradpour (2005); Want (2006); Marques et al. (2007); Santini (2008); Sequeira (2010); Rei (2010); Conti (2011); Zhu, Mukhopadhyay e Kurata (2012), Bachu, Saram e Kumas (2013) e Hashemi, Sarhaddi e Emami (2013)

A tag RFID pode ser anexada a um objeto ou acondicionada em diferentes materiais (tais como o plástico e o vidro), de vários formatos e tamanhos. O formato é importante porque determina a aplicabilidade e o desempenho do sistema de RFID. $O$ Quadro 5 apresenta os formatos e características das tags com sua figura representativa.

Um elemento-chave na operação de um sistema de RFID é a transferência de dados, que ocorre a partir da conexão entre uma tag e uma leitora. A leitora é um 
dispositivo que envia um sinal de rádio, o qual é recebido por todas as tags presentes no campo de radiofrequência e sintonizadas na mesma frequência. As tags recebem o sinal por meio das suas antenas e respondem transmitindo os dados armazenados nelas.

No entanto, interferências, em um sistema de RFID, podem provocar erros de transmissão de dados entre a tag e a leitora. Em razão de a radiofrequência ser analógica em vez de digital, ela fica suscetível a interferências provocadas pela presença de metais, alta umidade, líquidos, temperaturas extremas, motores elétricos/combustão, equipamentos sem fio (como o celular), entre outros.

Quadro 5 - Formatos, características e aparência das tags RFID

\begin{tabular}{|c|c|c|}
\hline Formato & Características & Figura \\
\hline Elipse & $\begin{array}{l}\text { O microchip e a antena são embutidos em uma } \\
\text { carcaça geralmente de resina epóxi ou } \\
\text { poliestirol. O formato de disco é usado quando } \\
\text { a etiqueta atinge uma faixa de temperatura } \\
\text { mais alta. O microchip varia de alguns } \\
\text { milímetros a } 10 \text { centímetros. }\end{array}$ & \\
\hline Plástico & $\begin{array}{l}\text { Mais comum devido à facilidade em adaptar } \\
\text { funcionalidades a eles. O formato de chaveiro e } \\
\text { outros objetos possuem uma carcaça mais } \\
\text { resistente e foi desenvolvido para situações } \\
\text { onde há necessidade de durabilidade. }\end{array}$ & \\
\hline Cartões & $\begin{array}{l}\text { Etiquetas embaladas na forma de cartão são } \\
\text { muito usadas por bancos para transformar os } \\
\text { cartões em não apenas cartões de banda } \\
\text { magnética ou ópticos, mas em um "cartão } \\
\text { esperto", os Smart Cards. O chip RFID está } \\
\text { dentro do cartão, que é formado por camadas } \\
\text { de plástico prensadas. }\end{array}$ & \\
\hline $\begin{array}{c}\text { Embarcada } \\
\mathrm{s}\end{array}$ & $\begin{array}{l}\text { Inseridas em objetos como relógios, roupas ou } \\
\text { braceletes. Usada geralmente para controle de } \\
\text { acesso e identificação de pessoas, como } \\
\text { exemplo, em hospitais para identificação de } \\
\text { pacientes e bebês e em escolas para identificar } \\
\text { alunos. }\end{array}$ & \\
\hline Vidro & $\begin{array}{l}\text { Desenvolvido para ser utilizado em ambientes } \\
\text { corrosivos ou imerso em líquidos ou, ainda, em } \\
\text { implantes subcutâneos. Seu tamanho é } \\
\text { bastante reduzido, podendo ter cerca de } 1 \text { (um) } \\
\text { centímetro. }\end{array}$ & \\
\hline Rótulo & $\begin{array}{l}\text { Produzido em maior escala. São fabricados em } \\
\text { formato de papel ou adesivo e podem receber } \\
\text { impressão por cima, como de uma máquina } \\
\text { impressora semelhante às usadas em códigos } \\
\text { de barras. }\end{array}$ & \\
\hline
\end{tabular}

Revista Produção Online, Florianópolis, SC, v. 16, n. 2, p. 633-677, abr./jun. 2016. 
Pelo fato de os sistemas de RFID transmitirem ondas eletromagnéticas, eles são classificados como sistemas de radiofrequência e não podem interferir em outros serviços de radiofrequência, tais como rádio, celular, televisão, sistemas do corpo de bombeiros e da polícia (MARQUES et al., 2009). A seleção da frequência de operação é determinada com base em exigências da aplicação, como velocidade, acurácia e condições ambientais, com normas e regulamentos que governam as aplicações específicas. O espectro eletromagnético no qual o sistema de RFID opera é dividido nas frequências baixa (LF), alta (HF), ultra-alta (UHF) e microondas.

Os sistemas de RFID podem ainda trabalhar com faixas de frequências reservadas, conhecidas como ISM - Industrial Scientific Medical. Cada faixa de frequência apresenta suas vantagens e desvantagens que dependem do tamanho da onda e da frequência, o que implica variáveis como alcance de leitura, taxa de transferência de dados (velocidade) entre a tag e o leitor, sua qualidade e uso, como consta no Quadro 6.

De acordo com Ahsan, Shah e Kingston (2010), a EPCglobal e a Organização Internacional para Padronização (ISO) são as principais organizações que trabalham para desenvolver padrões internacionais para as tecnologias RFID. Os padrões ISO 15961, 15962, 15963, 18000 e 18001 aplicam-se às técnicas de identificação e captura de dados para o gerenciamento de itens. Os autores supracitados comentam que essas duas organizações ainda estão em evolução e não são totalmente compatíveis. Assim, para evitar a utilização de diferentes frequências de padrão de rádio, a maior parte das comunidades internacionais é obrigada a cumprir as determinações da Internacional Normas Telecommunication Union (ITU). 
Quadro 6 - Atributos das frequências de operação RFID

\begin{tabular}{|c|c|c|c|c|}
\hline Atributo Tipo & LF & $\mathrm{HF}$ & UHF & Microondas \\
\hline Frequência & 30 a $300 \mathrm{kHz}$ & 3 a $30 \mathrm{MHz}$ & $300 \mathrm{MHz}$ a $3 \mathrm{GHz}$ & Maior que $3 \mathrm{GHz}$ \\
\hline $\begin{array}{l}\text { Frequência } \\
\qquad I S M\end{array}$ & $<135 \mathrm{kHz}$ & $\begin{array}{c}6,78 \mathrm{MHZ} ; 13,56 \mathrm{MHz} ; \\
\text { 21,125 MHz; } \\
\text { 40,680 MHz. }\end{array}$ & $\begin{array}{c}\text { 433,92 MHZ; } \\
869 \mathrm{MHz} ; 915 \mathrm{MHz} .\end{array}$ & $\begin{array}{c}2,45 \mathrm{GHz} ; 5,8 \mathrm{GHz} ; \\
24,125 \mathrm{GHz} .\end{array}$ \\
\hline $\begin{array}{l}\text { Alcance de } \\
\text { leitura }\end{array}$ & $\begin{array}{l}\text { Entre } 10 \mathrm{~cm} \mathrm{e} \\
50 \mathrm{~cm}\end{array}$ & Até 3 metros & Até 9 metros & $\begin{array}{l}\text { Maior que } \\
10 \text { metros }\end{array}$ \\
\hline Tipo da tag & Passiva & Passiva & Passiva e Ativa & Ativa \\
\hline $\begin{array}{c}\text { Taxa de } \\
\text { transferência }\end{array}$ & $\begin{array}{c}\text { Menor que } 1 \\
\text { Kbit/s }\end{array}$ & $\begin{array}{l}\text { Próximo de } \\
25 \mathrm{Kbit/s}\end{array}$ & $\begin{array}{c}\text { Próximo de } \\
30 \mathrm{Kbit/s}\end{array}$ & Até $1 \mathrm{Mbit} / \mathrm{s}$ \\
\hline Vantagens & $\begin{array}{c}\text { Funciona } \\
\text { melhor em } \\
\text { metais e } \\
\text { líquidos. Baixo } \\
\text { custo. }\end{array}$ & $\begin{array}{l}\text { Padrões comuns no } \\
\text { mundo. Bom alcance } \\
\text { de leitura. Média } \\
\text { taxa de transferência } \\
\text { de dados. As tags } \\
\text { são mais baratas que } \\
\text { as de LF. }\end{array}$ & $\begin{array}{c}\text { Alta taxa de } \\
\text { transferência de } \\
\text { dados. Alto alcance } \\
\text { de leitura. Identifica } \\
\text { diversas tags de } \\
\text { uma só vez. Pode } \\
\text { oferecer tags de } \\
\text { baixo custo. }\end{array}$ & $\begin{array}{c}\text { Alta taxa de } \\
\text { transferência de } \\
\text { dados (mais rápida } \\
\text { que UHF). Alto } \\
\text { alcance de leitura. }\end{array}$ \\
\hline Desvantagens & $\begin{array}{l}\text { Baixa taxa de } \\
\text { transferência de } \\
\text { dados. Baixo } \\
\text { alcance de } \\
\text { leitura. }\end{array}$ & $\begin{array}{l}\text { Baixo desempenho } \\
\text { em metais. }\end{array}$ & $\begin{array}{c}\text { Incompatível com } \\
\text { regulamentos } \\
\text { regionais. Suscetível a } \\
\text { interferências de } \\
\text { umidade, metais e } \\
\text { líquidos. }\end{array}$ & $\begin{array}{c}\text { Baixo desempenho } \\
\text { em metais e } \\
\text { líquidos. }\end{array}$ \\
\hline $\begin{array}{c}\text { Exemplos de } \\
\text { Aplicação }\end{array}$ & $\begin{array}{l}\text { Lojas e Fábricas. } \\
\text { Inventário e } \\
\text { controle de } \\
\text { acesso. } \\
\text { Identificar animais. } \\
\text { Automação } \\
\text { industrial. }\end{array}$ & $\begin{array}{l}\text { Papéis. Smart cards. } \\
\text { Controle de acesso. } \\
\text { Anti-falsificações. } \\
\text { Bagagem aérea. } \\
\text { Rastrear itens } \\
\text { pequenos. Identificar } \\
\text { pessoas. Prateleiras } \\
\text { inteligentes. }\end{array}$ & $\begin{array}{l}\text { Controle de acessos. } \\
\text { Controle de } \\
\text { inventário, } \\
\text { gerenciamento de } \\
\text { armazéns e } \\
\text { rastreamento de } \\
\text { ativos. }\end{array}$ & $\begin{array}{l}\text { Rastreamento de } \\
\text { veículos em } \\
\text { movimento. } \\
\text { Automação } \\
\text { industrial. }\end{array}$ \\
\hline
\end{tabular}

Fonte: Adaptado de Bhuptani e Moradpour (2005); Santini (2008); Marques e outros. (2009); Ahsan, Shah e Kingston (2010), Sequeira (2010); Rei (2010); Berz (2011); Conti (2011) e Asham (2011)

No Brasil, as regulamentações trabalham no espectro de $902 \mathrm{MHz}$ a $907,5 \mathrm{MHz}$ (UHF) e de $915 \mathrm{MHz}$ a $928 \mathrm{MHz}$ para produtos. A frequência padrão para dispositivos de identificação próximos é de 13,56 MHz (SANTINI, 2008). A Figura 10 mostra um mapa mundial da frequência de operação da RFID em UHF. Uma descrição detalhada das frequências de operação presentes nos países constantes desse mapa encontrasea no documento Regulatory status for using RFID in the EPC Gen 2 band (860 to $960 \mathrm{MHz}$ ) of the UHF spectrum, disponível no website da GS1 (www.gs1.org). 
Figura 10 - Mapa mundial da frequência de operação RFID em UHF

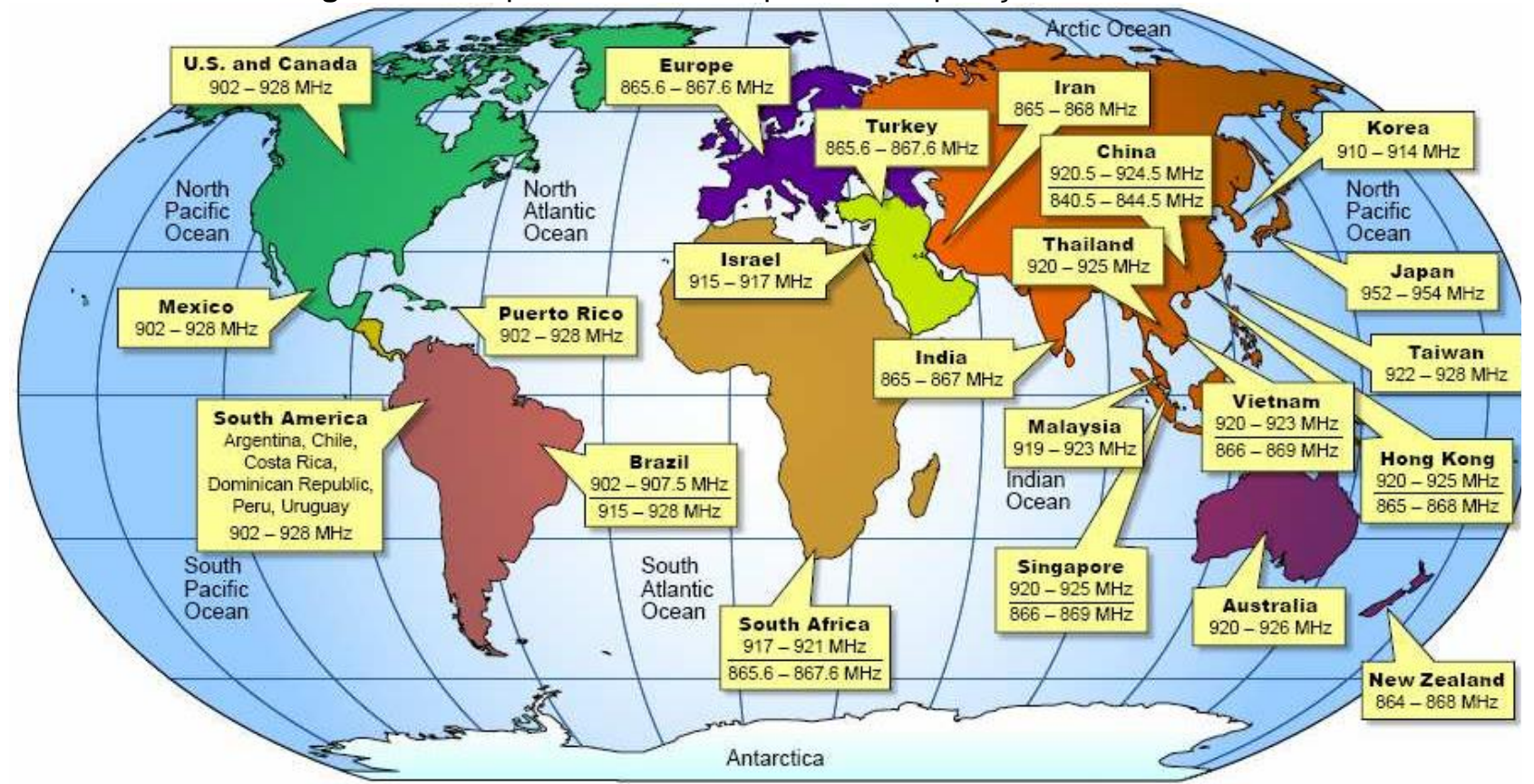

Fonte: Arizon Prid Techology (Yangzhou) CO., LTD (2014)

Para se criar valor a partir de toda a informação coletada, é necessária a utilização de um middleware, para se filtrarem os dados recolhidos. O middleware é composto por uma série de componentes de software que gerenciam o fluxo de informações entre os componentes de hardware de RFID (tags, antenas, leitores, sensores, impressoras) e os Sistemas Gerenciais (como o ERP - Enterprise Resources Planning e o SCM - Supply Chain Management).

Ilustra-se, na Figura 11, o funcionamento dessa tecnologia, desde a tag, passando pelas antenas, leitores e middleware, até os sistemas gerenciais. Cada item é brevemente explanado na sequência. 
Figura 11 - Funcionamento de um sistema RFID

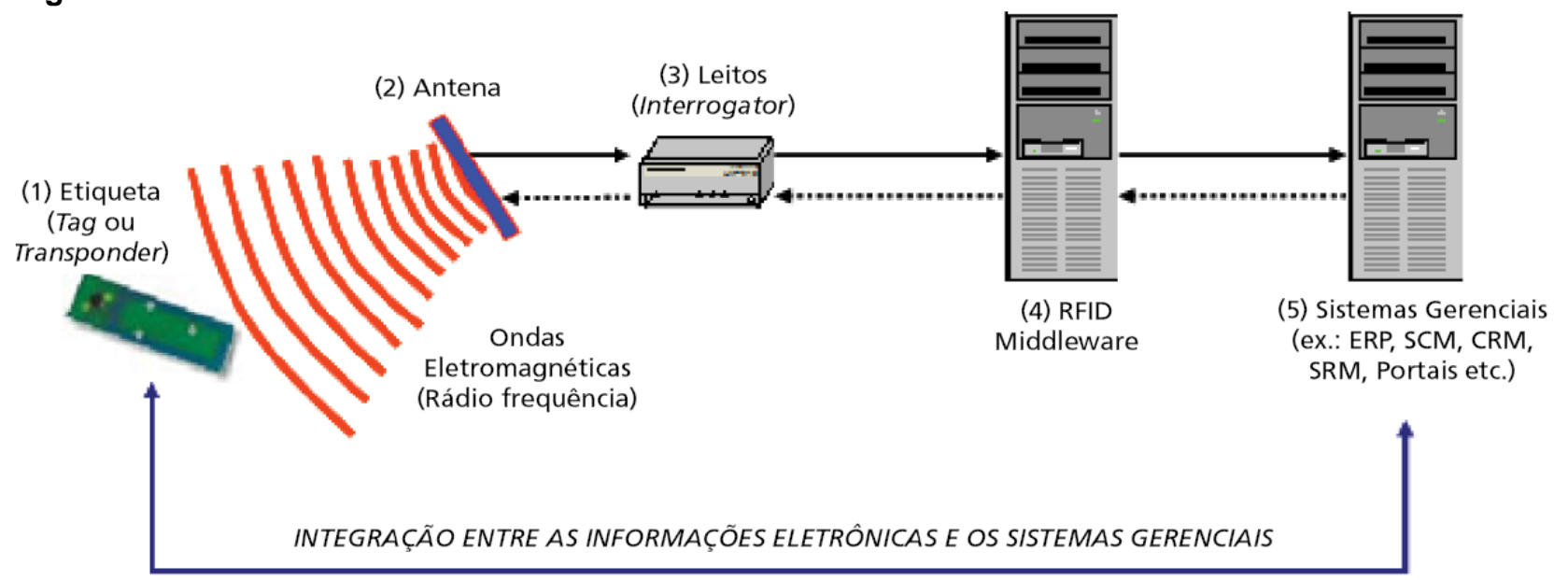

Fluxo de leitura das informações eletrônicas (das etiquetas para os sistemas gerenciais)

**..*...**..... Fluxo de gravação das informações eletrônicas (dos sistemas gerenciais para as etiquetas)

Fonte: Pedroso, Zwicker e Souza (2009)

Conforme Figura 11, Pedroso, Zwicker e Souza (2009) explicam que as informações de um produto são registradas nas etiquetas para RFID (1). Essa etiqueta é fixada no produto, e as informações contidas nela são lidas pela antena (2) e pelos leitores (3), por meio de radiofrequência. A gestão das informações distribuídas ao longo da cadeia de suprimentos é realizada pelo middleware (4). Esse componente gerencia o fluxo de informações entre os hardwares de RFID (antenas, leitores, sensores, impressoras de RFID), identifica os eventos associados a essas informações (por exemplo, uma caixa que passou por um ponto de recebimento pode registrar uma atualização de estoques) e realiza a integração com os sistemas gerenciais (5). O fluxo de informação pode ocorrer das etiquetas para os sistemas gerenciais (fluxo de leitura) e destes para as etiquetas (fluxo de gravação), possibilitando uma integração entre as informações eletrônicas e os sistemas gerenciais.

Apesar da sua utilidade, a RFID apresenta vantagens e desvantagens segundo avaliações de diferentes autores, conforme mostrado no Quadro 7. 
Quadro 7 - Vantagens e desvantagens da RFID

\begin{tabular}{|c|c|c|c|c|c|c|c|c|c|c|c|c|c|c|c|c|c|}
\hline & \multirow{2}{*}{ Descrição } & \multicolumn{16}{|c|}{ Autores } \\
\hline & & 1 & 2 & 3 & 4 & 5 & 6 & 7 & 8 & 9 & 10 & 11 & 12 & 13 & & $4 \mid 1$ & \\
\hline \multirow{17}{*}{ 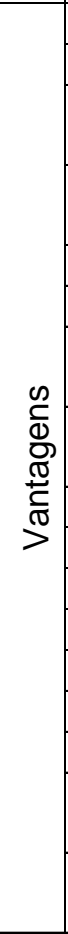 } & Apoio/reduz custos nas operações logísticas. & & & $\mathrm{x}$ & & & & & & $\mathrm{x}$ & $\mathrm{x}$ & & $\mathrm{x}$ & & & & \\
\hline & Aplicação em diversas áreas de operações. & & $\mathrm{x}$ & $\mathrm{x}$ & $\mathrm{x}$ & & & & & $\mathrm{x}$ & & & $\mathrm{x}$ & & & & \\
\hline & $\begin{array}{l}\text { Integra atividades da cadeia de suprimentos } \\
\text { além dos limites organizacionais/países. }\end{array}$ & & & & & & & & & $\mathrm{x}$ & & & & & & & \\
\hline & $\begin{array}{l}\text { A leitora não precisa ser direcionada para } \\
\text { leitura do item etiquetado (linha de visão). }\end{array}$ & $x$ & $\mathrm{x}$ & $\mathrm{x}$ & $x$ & $\mathrm{x}$ & & & & $\mathrm{x}$ & & $\mathrm{x}$ & $\mathrm{x}$ & $\mathrm{x}$ & $x$ & & \\
\hline & Identificação automática e simultânea de itens. & & $\mathrm{x}$ & $\mathrm{x}$ & & $\mathrm{x}$ & & & $\mathrm{x}$ & & $\mathrm{x}$ & $\mathrm{X}$ & $\mathrm{x}$ & $x$ & $x$ & & \\
\hline & Atinge distâncias de leitura de vários metros. & & $\mathrm{x}$ & & & & & & & & & & & & & & \\
\hline & $\begin{array}{l}\text { Visibilidade ao longo da cadeia de } \\
\text { abastecimento. }\end{array}$ & & $\mathrm{x}$ & & & $x$ & & & & $x$ & $x$ & & $\mathrm{x}$ & & & & \\
\hline & $\begin{array}{l}\text { As etiquetas podem conter até mais } \\
\text { informações do que uma simples identificação. }\end{array}$ & & $\mathrm{x}$ & $\mathrm{x}$ & & & & & & & & & $\mathrm{x}$ & $\mathrm{x}$ & & & \\
\hline & Capacidade de gravação/regravação de dados. & & $\mathrm{x}$ & $\mathrm{x}$ & $\mathrm{x}$ & $\mathrm{x}$ & & & & $\mathrm{x}$ & & & & & & & \\
\hline & Precisão e velocidade na identificação de itens. & & $\mathrm{x}$ & & & $\mathrm{x}$ & & & $\mathrm{x}$ & $\mathrm{x}$ & $\mathrm{x}$ & $\mathrm{x}$ & $\mathrm{x}$ & & & 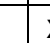 & $\mathrm{x}$ \\
\hline & Durabilidade das etiquetas. & & & $\mathrm{x}$ & $\mathrm{x}$ & $\mathrm{x}$ & & & & $\mathrm{x}$ & & & & $\mathrm{x}$ & & & \\
\hline & Reciclagem inteligente de produtos. & & & & & $\mathrm{x}$ & & & & & & & & & & & \\
\hline & Vários tipos e formatos. & & $\mathrm{x}$ & $x$ & $\mathrm{x}$ & & & & $\mathrm{x}$ & & & & & & & & \\
\hline & Limita as possibilidades de erro humano. & & & $\mathrm{x}$ & & & & & & & $\mathrm{x}$ & & & & & 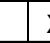 & $\mathrm{x}$ \\
\hline & Reduz mão de obra em função da automacão. & & & & & & & & & $\mathrm{x}$ & $\mathrm{x}$ & & & & & & \\
\hline & $\begin{array}{l}\text { Suporta ambientes agressivos, com presença } \\
\text { de gelo, fogo, gordura, ruído e temperaturas. }\end{array}$ & & & & $x$ & & & & & & & $\mathrm{x}$ & & & & & \\
\hline & $\begin{array}{l}\text { Permite adequar preceitos legais } \\
\text { responsabilidade compartilhada. }\end{array}$ & & & & $\mathrm{x}$ & & & & & & & & & & & & $\mathrm{x}$ \\
\hline \multirow{14}{*}{ 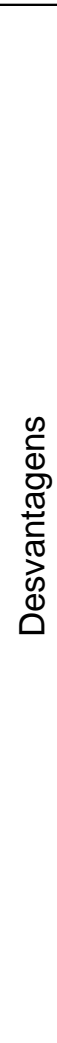 } & Custo elevado da tecnologia. & & $\mathrm{x}$ & $\mathrm{x}$ & $\mathrm{x}$ & $\mathrm{x}$ & & $\mathrm{x}$ & $\mathrm{x}$ & $\mathrm{x}$ & $\mathrm{x}$ & $\mathrm{x}$ & $\mathrm{x}$ & & & & \\
\hline & $\begin{array}{l}\text { Campos eletromagnéticos de outros } \\
\text { equipamentos podem interferir na comunicação } \\
\text { entre leitor e etiqueta. }\end{array}$ & $\mathrm{x}$ & $\mathrm{x}$ & & $\mathrm{x}$ & & $\mathrm{x}$ & & $\mathrm{x}$ & $\mathrm{x}$ & & & & & & & \\
\hline & $\begin{array}{l}\text { Condições ambientais, metais e líquidos } \\
\text { interferem na comunicação entre leitor/etiqueta. }\end{array}$ & $x$ & $x$ & & & $x$ & & & & & $\mathrm{x}$ & & & & & & \\
\hline & Vários regulamentos/padrões mundiais RFID. & $\mathrm{x}$ & $\mathrm{x}$ & & & & $\mathrm{x}$ & $\mathrm{x}$ & & $\mathrm{x}$ & & & $\mathrm{x}$ & & & & \\
\hline & $\begin{array}{l}\text { Ainda não existe integração entre os } \\
\text { fabricantes. }\end{array}$ & $\mathrm{x}$ & & & & & & & & & & & & & & & \\
\hline & $\begin{array}{l}\text { Frequência de operação pode interferir com } \\
\text { outros serviços que usam radiofrequência. }\end{array}$ & & $\mathrm{x}$ & & $\mathrm{x}$ & & & & & & & & $\mathrm{x}$ & & & & \\
\hline & Diferentes frequências de operação. & & & & $\mathrm{x}$ & $\mathrm{x}$ & & & & & & & & & & & \\
\hline & $\begin{array}{l}\text { Operação de vários leitores no mesmo } \\
\text { ambiente provoca interferências entre esses } \\
\text { leitores. }\end{array}$ & & & & & & $\mathrm{x}$ & & & & $\mathrm{x}$ & & $\mathrm{x}$ & & & & \\
\hline & Necessidade de TI (Tecnologia da Informação). & $\mathrm{x}$ & & & & & & & & $\mathrm{x}$ & $\mathrm{x}$ & & $\mathrm{x}$ & & & -2 & $x$ \\
\hline & $\begin{array}{l}\text { Invasão da privacidade dos consumidores por } \\
\text { causa da monitoração das etiquetas fixadas nos } \\
\text { produtos. }\end{array}$ & & $\mathrm{x}$ & $\mathrm{x}$ & $\mathrm{x}$ & $x$ & & $\mathrm{x}$ & & $\mathrm{x}$ & & & $\mathrm{x}$ & & & & \\
\hline & Tecnologia com elevado grau de obsolescência. & & & & & & & & & & & $\mathrm{x}$ & & & & & \\
\hline & $\begin{array}{llll}\text { Implicação } & \text { global } & \text { requer } & \text { estudos } \\
\text { transnacionais. } & & & \end{array}$ & & & & & & & & & $\mathrm{x}$ & & & & & & & \\
\hline & $\begin{array}{l}\text { Resistência à cooperação entre as diferentes } \\
\text { camadas da cadeia de suprimentos. }\end{array}$ & & & & & & & & & $\mathrm{X}$ & & & & & & & \\
\hline & $\begin{array}{l}\text { Vulnerável a riscos de segurança (facilidade de } \\
\text { acesso às tags ou banco de dados). }\end{array}$ & & & & & & & & & $\mathrm{x}$ & & & & & & & \\
\hline
\end{tabular}

Fonte: Adaptado de 1-Banzato (2005); 2-Bhuptani e Moradpour (2005); 3-Want (2006); 4-Santini (2008); 5-Leite e outros (2008); 6-Marques e outros (2009); 7-Rei (2010); 8-Ahsan, Shah e Kingston (2010); 9-Park, Koh e Nam (2010): 10-Sequeira (2010); 11-Conti (2011); 12-Zhu, Mukhopadhyay e Kurata (2012); 13-Ramanathan, Bentley e Ko (2012). 14-Bachu, Saram e Kumas (2013); 15-Xavier e Corrêa (2013)

Revista Produção Online, Florianópolis, SC, v. 16, n. 2, p. 633-677, abr./jun. 2016. 
Um estudo realizado por Leite et al. (2008) revelou que as maiores barreiras para o uso da tecnologia de RFID são: i) o custo elevado em relação aos sistemas de código de barras, ii) o aumento no preço final dos produtos, iii) a necessidade de padronização das frequências de operação, e iv) o uso em materiais metálicos e condutivos relativos ao alcance de transmissão das antenas.

Ainda são muitos os desafios que permeiam a inovação tecnológica da RFID, tanto que revistas importantes, como Production and Operations Management, International Journal of Economics Production, IEEE Journal Systems e IEEE Transactions on Automation Science and Engineering, estão produzindo edições especiais sobre o tema (ZHU; MUKHOPADHYAY; KURAT, 2012). No Brasil, ainda há poucas informações sobre o uso da RFID (LEITE et al., 2008), mas algumas empresas já vêm aplicando essa tecnologia (PEDROSO; ZWICKER; SOUZA, 2009). Em resumo, a RFID tem expandido sua capacidade, vem sendo rapidamente absorvida (CONTI, 2011) e tem apresentado grande aceitação, principalmente pela possibilidade de contribuir para a integração dos processos de rastreabilidade (BATOCCHIO, 2011).

\section{COMPARATIVO ENTRE AS TECNOLOGIAS DE CÓDIGO DE BARRAS E DE RFID}

Sendo o código de barras e a RFID objetos deste estudo, realizou-se um comparativo entre essas duas tecnologias, de forma a se tornarem mais visíveis os pontos em comum e os pontos divergentes, conforme mostrado no Quadro 8.

Quadro 8 - Comparativo das tecnologias do código de barras e RFID

\begin{tabular}{|c|c|c|}
\hline Características & Código de Barras & RFID \\
\hline Resistência mecânica & Baixa & Alta \\
\hline Formatos & Etiquetas & Variados \\
\hline Exige contato visual & Sim & Não \\
\hline Vida útil & Baixa & Alta \\
\hline Possibilidade de escrita & Não & Sim \\
\hline Leitura simultânea & Não & Sim \\
\hline Dados armazenados & Baixa & Alta \\
\hline Funções adicionais & Não & Sim \\
\hline Segurança & Baixa & Alta \\
\hline Custo inicial & Baixo & Alto \\
\hline Custo de manutenção & Baixo & Alto \\
\hline Reutilização & Não & Sim \\
\hline
\end{tabular}

Fonte: adaptado de Sequeira (2010) 
A tecnologia de RFID supera o código de barras em quase todos os parâmetros, mas as vantagens deste sobre a RFID é o menor custo de implementação e manutenção (SEQUEIRA, 2010).

\section{ESTUdO DE CASO: TECNOLOGIA DE IDENTIFICAÇÃO DE PRODUTOS E A LOGÍSTICA REVERSA NA INDÚSTRIA ELETROELETRÔNICA}

Apesar das problemáticas e estatísticas discutidas, Lavez, Souza e Leite (2011) enfatizam que a $L R$ reduz os impactos ambientais causados pelos REEE e proporciona processos produtivos sustentáveis. A esse respeito, surge a seguinte pergunta: qual a contribuição da tecnologia de identificação de produtos para a LR dos REEE?

Esse questionamento é relevante, visto que: Santini (2008) defende a adoção da RFID nos processos de reciclagem, para se atender à legislação ambiental; Lee e Chan (2009) sugerem o uso da RFID na LR, para se identificarem os produtos devolvidos e componentes reutilizáveis; e Xavier e Corrêa (2013), Sasaki (2013) e Valle e Souza (2014) julgam que a RFID e o código de barras trazem uma nova extensão à $L R$, sendo uma forma potencial de identificação dos produtos nos estágios do seu ciclo de vida.

Com o intuito de elucidar o contexto da pesquisa, examina-se, nesta seção, o projeto SmartWaste da Hewlett-Packard (HP) do Brasil, que utiliza a RFID na LR de REEE. A escolha da HP Brasil como empresa a ser estudada deve-se a seu pioneirismo no desenvolvimento de soluções em gestão de resíduos. A escolha do SmartWaste como o projeto a ser analisado é devida à sua inovação e reconhecimento mundial em soluções de RFID como gestão do ciclo de vida dos produtos HP.

O projeto busca aperfeiçoar a capacidade da empresa de ofertar produtos de qualidade a custos mais baixos. Por isso, há restrição quanto a divulgação dos resultados do SmartWaste (EC, 2008), evidenciando carência de informações sobre ele na literatura mundial.

\subsection{A Hewlett-Packard (HP)}

Fundada em 1939 nos Estados Unidos, a HP é uma empresa fabricante de produtos da linha verde (desktops, notebooks, impressoras e componentes). Ela opera 
em mais de 170 países, emprega 302 mil pessoas, possui um portfólio de mais de dois mil produtos e mais de 36 mil patentes (HP, 2014). Com mais de um bilhão de clientes, o faturamento líquido da HP em 2014 foi de US\$111,45 bilhões (ABDI, 2015b).

O tema sustentabilidade é prioridade na HP e está inserido na estratégia de negócios e em toda a cadeia produtiva. Um exemplo, nesse sentido, é o programa Design for Environment, criado em 1992, que tem como objetivo projetar os produtos de modo a facilitar sua reciclagem. Com suas iniciativas, a HP é mundialmente reconhecida como a empresa líder no seu setor nos programas de gestão de resíduos eletroeletrônicos. Desde 1987, quando iniciou seus programas, a HP reciclou 1,683 milhão de toneladas de hardware no mundo. Com programas de reciclagem em 73 países, a taxa de reutilização e reciclagem da HP já atinge $12 \%$ das vendas (HP, 2014).

A HP Brasil, por sua vez, tem mais de 45 anos de história no país, emprega 8,5 mil pessoas e conta com 27 mil canais de venda e distribuição (HP, 2011). A unidade brasileira exporta impressoras para Argentina, Chile, Peru, Bolívia e Uruguai. Além disso, a HP Brasil participa como membro da ABINEE nas discussões técnicas para a normatização do setor, e conta com a parceria do CEMPRE (Centro Empresarial para a Reciclagem) para a habilitação de cooperativas de catadores, que atuem na devolução de embalagens de produtos (KRUGLIANSKAS; CUZZIOL, 2014).

\subsection{O início da aplicação da RFID na HP}

Como um fornecedor mundial de eletroeletrônicos, a HP enfrenta vários desafios no mercado, dentre eles: i) a concorrência global, ii) os altos custos resultantes da dependência de uma cadeia de valor norteada pela tecnologia, e, iii) com uma das mais complexas cadeias de suprimento do mundo, gasta US\$ 50 bilhões por ano na aquisição de materiais, componentes, fabricação e distribuição de seus produtos (EC, 2008). Devido à sua natureza competitiva, a HP busca continuamente aperfeiçoar seus processos e eliminar deficiências, e a RFID ofereceu um potencial para atender às suas necessidades.

A HP começou a explorar a tecnologia de RFID em 2002 em quatro de suas fábricas, duas em Manchester, Virginia, e duas em Memphis, Tennessee (HP, 2004). 
Conforme ABDI (2015a), as razões que levaram a HP a adotar a RFID foram: i) atingir os requisitos do cliente Walmart relativos à RFID por meio da etiquetagem de caixas e paletes, ii) melhorar a eficiência da cadeia de fornecimento por meio da redução do custo de mão de obra envolvida, iii) aumentar a velocidade das operações e sua qualidade por meio do aumento da precisão na primeira passagem, e iv) aperfeiçoar o sistema de coleta de dados.

Logo no início, a HP reconheceu os benefícios que a RFID poderia trazer às operações da empresa. Em Memphis, por exemplo, a HP identificou que o processo de preparação de um palete para expedição foi reduzido de 90 para 11 segundos. A RFID também eliminou a necessidade de leituras demoradas do código de barras. Em Chester, os custos com o manuseio de embalagem e paletes reduziu significativamente devido à diminuição do número de erros manuais (CHUANG; SHAW, 2007). Diante desses resultados e com o apoio de sua liderança, a HP avançou nos estudos da RFID e criou Centros de Excelência em RFID, para testar o uso desse sistema em sua própria cadeia.

\subsection{O Projeto SmartWaste}

Em 2004, a HP iniciou um projeto-piloto em seu Centro de Excelência em RFID (RFID-CoE), localizado em Sorocaba, São Paulo. O RFID-CoE reproduz, em suas instalações, o ambiente de uma linha de produção, podendo simular todo o processo de fabricação de um equipamento etiquetado com tags RFID, bem como seu comportamento na manufatura.

Com o projeto, a HP pretendia integrar a RFID numa cadeia end-to-end, abrangendo fabricação, distribuição, reparação, logística reversa e reciclagem (RFID$\mathrm{CoE}, 2015)$. O projeto foi concebido para estabelecer o rastreamento dos produtos em fim de vida, assegurando seu descarte adequado e, principalmente, quantificando o material recolhido, a fim de reinserir a matéria-prima reciclada na fabricação de novos produtos (HP, 2011). Com isso, a HP esperava atingir suas metas de sustentabilidade e fechar o ciclo do produto.

A HP enfrentou alguns desafios no decorrer do projeto. Um deles era o de melhorar o desempenho da taxa de leitura e escrita das tags RFID fixadas nas 
impressoras encaixotadas em paletes com até 108 produtos empilhados (XAVIER et al, 2010). Devido à alta densidade de metais nos produtos, as transmissões das tags dificilmente seriam captadas, salvo se os leitores das antenas tivessem orientação que combinassem com a posição das tags sobre o palete. Dessa forma, o palete foi regulado várias vezes, a fim de se obter a leitura de cada tag. A leitura completa de um palete carregado de impressoras etiquetadas durava 60 segundos (RFID JOURNAL, 2015).

Diante disso, o RFID-CoE desenvolveu uma estrutura metálica contendo um braço giratório equipado com um leitor de tags em sua extremidade (Figura 12). Quando um palete era colocado na estrutura, o braço girava em torno dele e efetuava a leitura das tags.

Figura 12 - Estrutura metálica contendo braço giratório com leitor de tags RFID

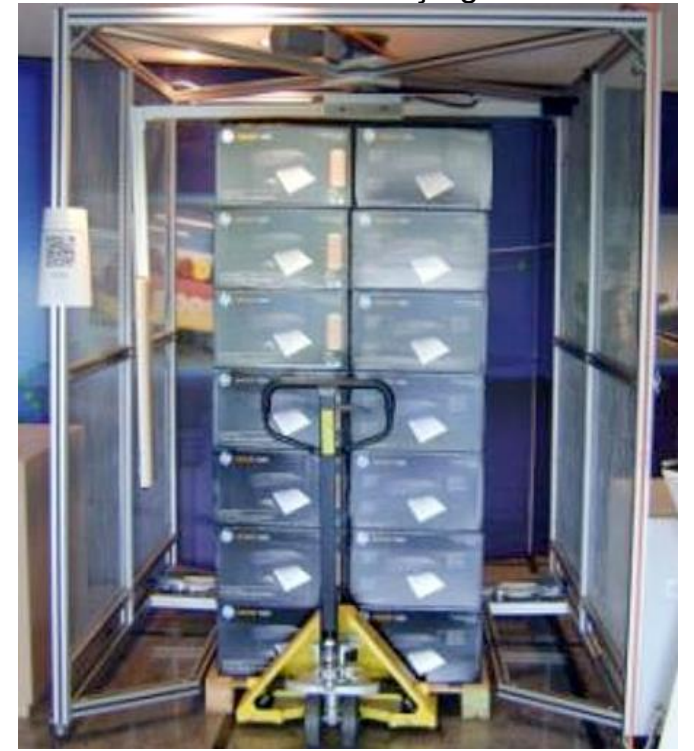

Fonte: RFID Journal (2015)

Em 2007, com o uso da RFID no braço giratório, o tempo de leitura de um palete reduziu para 37 segundos. Nesse mesmo ano, o RFID-CoE desenvolveu um túnel com leitores RFID para capturar dados de todas as tags fixadas nos produtos embalados nas caixas. Dois anos depois, esses túneis eram utilizados para a leitura das tags de até 60 cartuchos acondicionados por caixa (RFID JOURNAL BRASIL, 2015). 
O projeto-piloto foi bem-sucedido e obteve reconhecimento mundial. O programa SmartWaste de reciclagem por meio de RFID começou em julho de 2011. A evolução do emprego da RFID na HP Brasil, em Sorocaba, é mostrada na Figura 13.

Figura 13 - Linha do Tempo RFID HP Brasil - principais fases

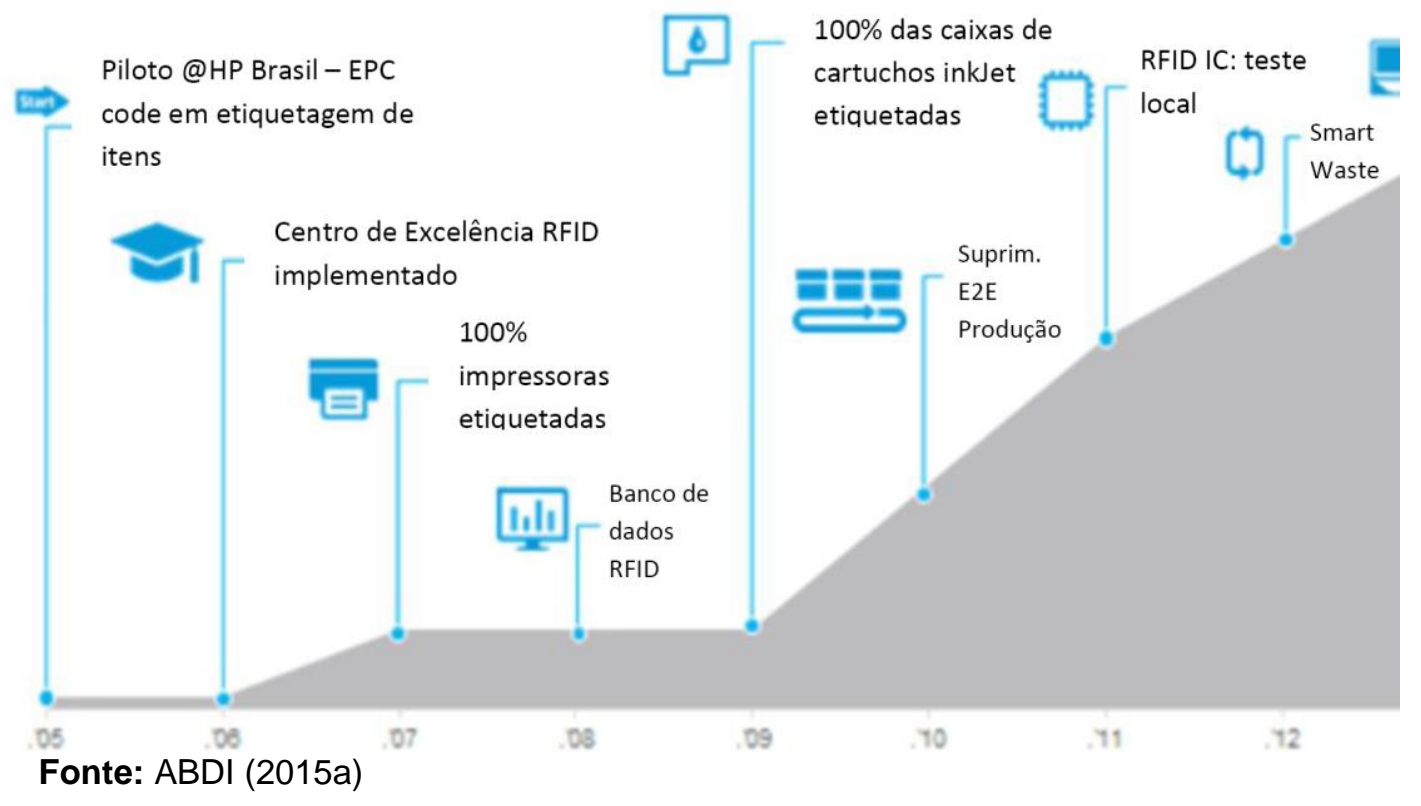

Contando com empresas parceiras situadas na cidade, como a Flextronics (fabricante de eletroeletrônicos), Sinctronics (soluções sustentáveis em eletroeletrônicos), Flextronics Instituto de Tecnologia (desenvolvimento de softwares) e o RFID-CoE, a fábrica da HP em Sorocaba passou a ser o primeiro Centro de Reciclagem de Cartuchos HP da América Latina. A Figura 14 mostra o ecossistema do centro de inovação e tecnologia da Sinctronics. 
Figura 14 - O ecossistema da Sinctronics (parceira HP)

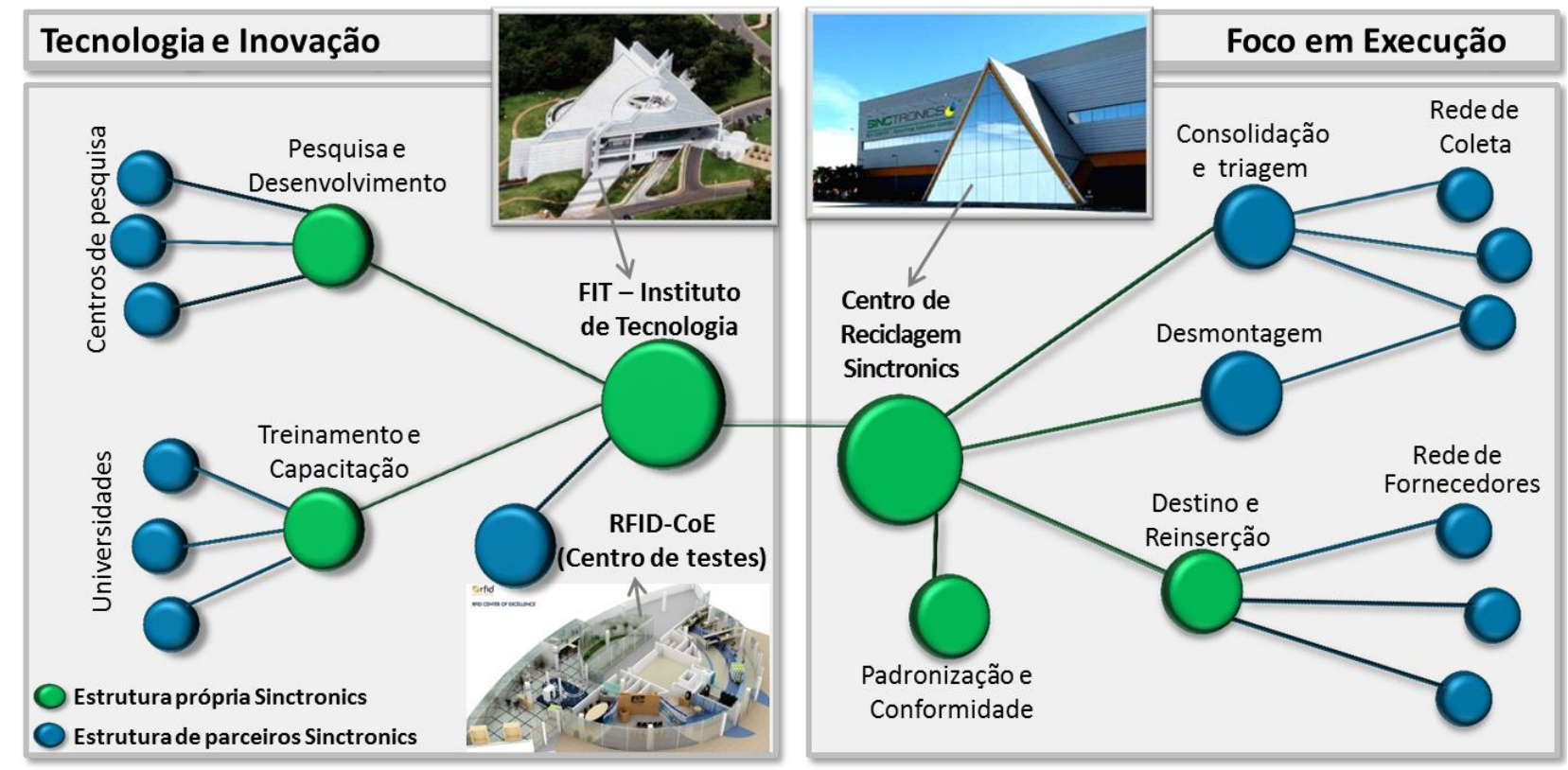

Fonte: adaptado de Sinctronics (2015)

A Sinctronics é um centro de referência que oferece soluções completas em reciclagem de eletroeletrônicos. Ela integra Logística Reversa, processamento de materiais, investimentos em pesquisa e desenvolvimento, inclusão social e educação ambiental.

\subsection{O Processo Produtivo SmartWaste}

As tags RFID são fixadas nos produtos HP e passam por todo o processo, desde recebimento, manufatura e distribuição até o retorno dos itens para reciclagem. Os detalhes dessa cadeia de valor são discutidos a seguir.

A fábrica HP de Sorocaba utiliza tags produzidas pela Ceitec, empresa brasileira vinculada ao Ministério da Ciência, Tecnologia e Inovação. As tags são passivas e operam na frequência UHF $950 \mathrm{MHz}$ (ANGELES, 2013) com o padrão EPC Gen2 (DEPA, 2015). O EPC Gen2 funciona em qualquer lugar do mundo, e muitos fabricantes de chips e tags alinham-se a ele. As tags são interrogadas por leitores Mercury5 da ThingMagic do tipo IP52, são resistentes à água e oferecem proteção contra a entrada de poeiras (ANGELES, 2013). 
Conforme RFID-CoE (2015), enquanto as impressoras são montadas na fábrica parceira da HP, o EPC é gerado e dados importantes são gravados nas tags, como o número de série, a composição, a versão do firmware, a validade do cartucho e o país de destino, gerando uma espécie de "DNA" do produto para seu futuro reaproveitamento. O próximo passo é fixar essas tags no chassi das impressoras, nos cartuchos de tinta e nos tôneres. Em seguida, os produtos etiquetados são testados e armazenados em paletes. No interior da manufatura, na medida em que os produtos estão no alcance das antenas que se localizam nas entradas e saídas da área de armazenagem, as leituras das tags são realizadas, e as informações são lançadas conforme a entrada e saída dos produtos em estoque. Essa cadeia de valor é mostrada na Figura 15.

Figura 15 - Cadeia de valor dos produtos HP baseada em RFID - manufatura e logística.

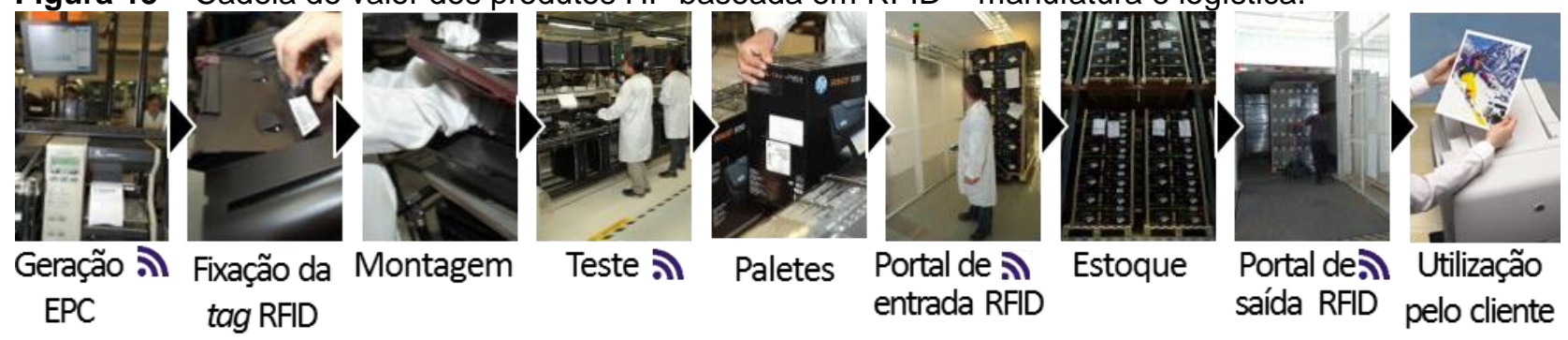

Fonte: adaptado de Pandini (2012).

No intuito de integrar a reciclagem com base em RFID nessa cadeia de valor, a HP complementou a Logística Reversa e reciclagem e fechou o ciclo do seu produto por meio do projeto SmartWaste. Os detalhes dessa incorporação serão discutidos a seguir.

Com o programa de reciclagem HP Planet Partners, os clientes devolvem os produtos dirigindo-se a um dos pontos de coleta após terem criado uma requisição no site da HP ou por e-mail. Desse modo, a HP recebe entre 40 e 50 toneladas de produtos em fim de vida por mês, dentre os quais estão 25 mil tôneres e cartuchos vazios (KRUGLIANSKAS; CUZZIOL, 2014). Conforme RFID Journal (2015), rotineiramente, caminhões carregados de produtos em fim de vida chegam ao Centro de Reciclagem, em Sorocaba. Os trabalhadores que descarregam os produtos utilizam leitores de RFID na identificação e armazenagem deles, a fim de facilitarem a posterior 
desmontagem e separação de seus componentes. Os produtos que não possuem tags são identificados manualmente.

Quando os produtos em fim de vida entram no processo devidamente etiquetados, o SmartWaste identifica e quantifica cada característica dos itens por meio da RFID. São registrados eletronicamente todos os componentes do produto rastreado, como vidro, metal, borracha, plástico, entre outros, possibilitando a correta separação, contagem e aproveitamento de cada item na fabricação de novos produtos HP e de outros segmentos industriais (RFID-CoE, 2015).

Todas as informações capturadas pelas tags são enviadas para um sistema gerencial (um software) desenvolvido exclusivamente para esse projeto. A partir dos dados recebidos, o sistema gerencial gera gráficos e relatórios. A Figura 16, por exemplo, ilustra uma tela desse software com a quantidade de material reciclado e os produtos e materiais mais reciclados. Todos eles referentes ao ano de 2012.

Figura 16 - Identificação das matérias-primas a serem recicladas por meio do SmartWaste - 2012

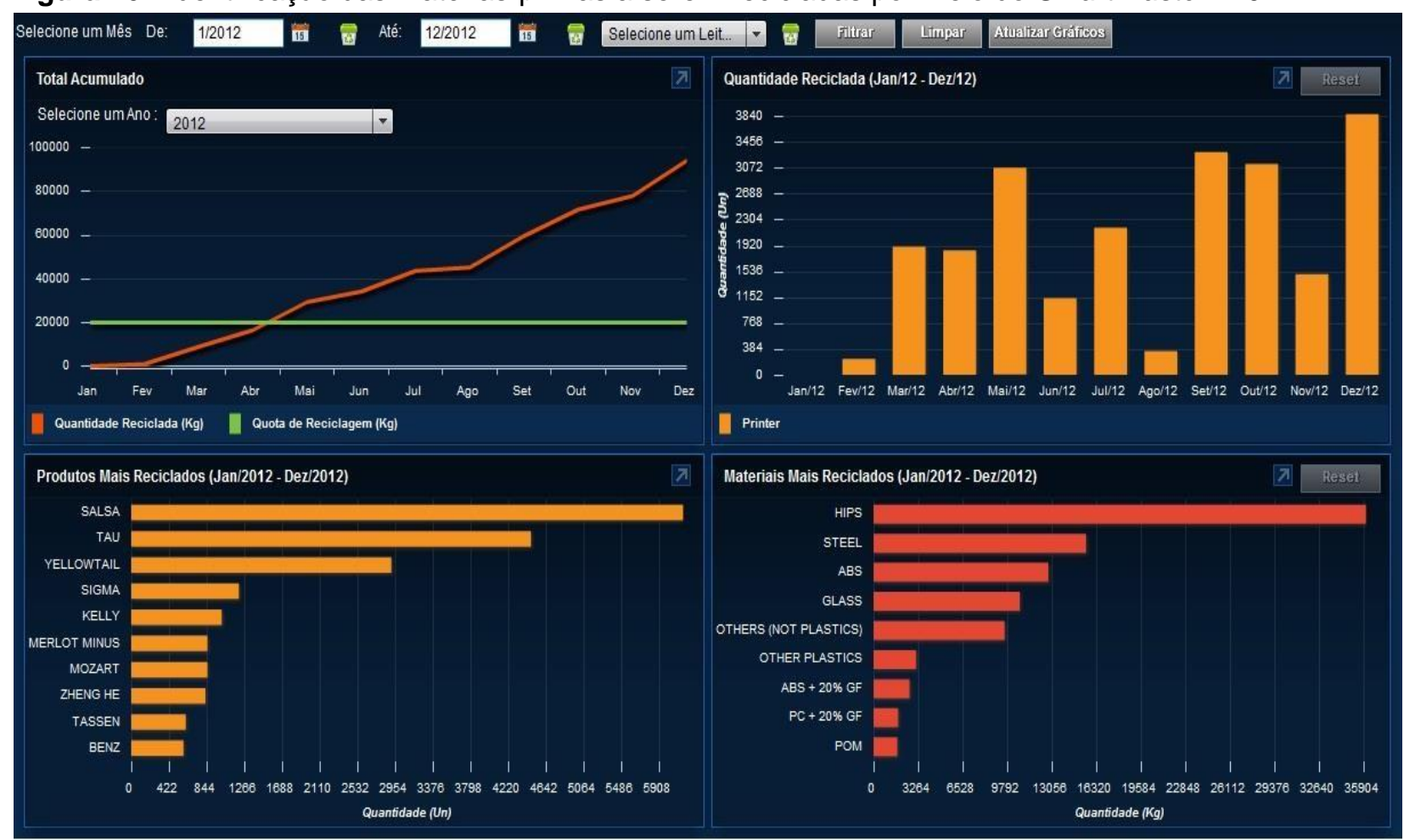

Fonte: Ohde (2013)

Conforme HP (2015b), no Centro de Reciclagem, o processo de reciclagem dos cartuchos HP começa com a separação por modelo. O circuito elétrico é removido e Revista Produção Online, Florianópolis, SC, v. 16, n. 2, p. 633-677, abr./jun. 2016. 
enviado para uma empresa que recupera metais preciosos. A tampa com etiqueta é separada e direcionada a uma indústria que fabrica papel plastificado. A espuma de tinta é retirada e aproveitada na indústria da construção civil, gerando energia para a fabricação de cimento. $O$ circuito de impressão é removido e também é destinado à recuperação de metais preciosos. O corpo do cartucho passa por um processo diferenciado de lavagem e secagem e, em seguida, é triturado. O material reciclado é misturado com garrafas PET, e a matéria-prima, usada em até $70 \%$ da composição plástica de novos cartuchos. Em seu Centro de Reciclagem, a HP Brasil também recicla modelos de cartuchos de tinta de impressoras de grandes formatos, que imprimem banners, livros, revistas e outros materiais. Essa matéria-prima, reciclada dos cartuchos HP, é utilizada na composição de novas impressoras HP produzidas no país.

Todas as ações discutidas contribuíram para que a HP atingisse seu objetivo de integrar a RFID na cadeia end-to-end, abrangendo fabricação, distribuição, reparação, Logística Reversa e reciclagem. Com isso, a empresa garante produtos de fontes confiáveis, oferece controle ao longo da cadeia de valor, melhora a relação com os seus clientes quanto às metas de sustentabilidade e proporciona o fechamento do ciclo do produto. A Figura 17 mostra a cadeia end-to-end da HP Brasil.

Figura 17 - Cadeia integrada end-to-end da HP Brasil em Sorocaba.

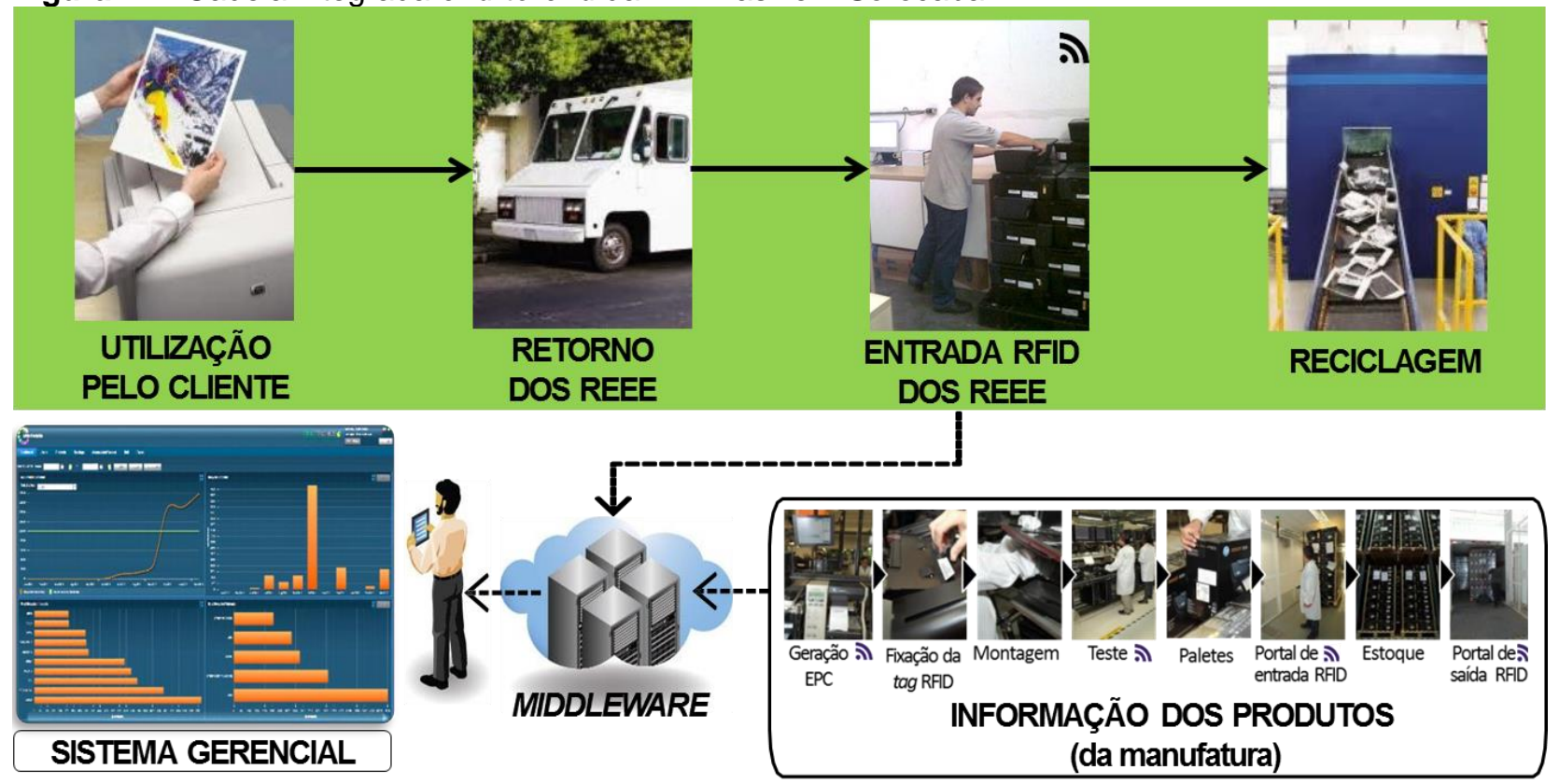

Fonte: adaptado de Pandini (2012) 
Conforme a Figura 17, o produto HP em fim de vida retorna à fábrica e, em seguida, é realizada a leitura por RFID dele. Os dados são ligados às informações que se tem daquele produto, mostrando o quanto de cada item está retornando ao processo.

\subsection{Os resultados da implantação da RFID e do SmartWaste na HP}

O projeto de implantar a tecnologia de RFID na HP é um dos casos mais destacados no mundo em termos de alcance de objetivos (XAVIER et al, 2010). Segundo ADBI (2015a;b), a cadeia de valor da HP Brasil: i) assegurou a integridade física dos conteúdos dos paletes, ii) garantiu o controle individual do produto e a sua rastreabilidade, iii) passou a controlar os tempos de produção e gerar dados para melhoria dos processos, iv) aumentou a eficiência na gestão de estoques, como o controle FIFO (First in - First out) e o tempo no estoque de produtos acabados, v) reduziu os erros internos para valores inferiores a $100 \mathrm{ppm}$, vi) automatizou os processos internos de movimentação dos produtos e vii) permitiu informar previamente aos clientes os dados de embarque de cada produto adquirido.

Desde 2011, quando iniciou o programa SmartWaste, a HP: i) investiu mais de $\mathrm{R} \$ 17$ milhões em pesquisa e desenvolvimento da tecnologia de RFID no país (RFID JOURNAL BRASIL, 2015), ii) inseriu tags em mais de 10 milhões de impressoras, iii) reciclou mais de 1,2 milhão de cartuchos (HP, 2011) e iv) incrementou 312,76 \% na coleta e segregação. Além disso, mais de 43 mil impressoras foram rastreadas, o que equivale a 178,5 toneladas de matérias-primas recicláveis (GS1 BRASIL, 2015). O tempo de leitura de um palete por meio da estrutura metálica com braço giratório reduziu para 14 segundos, e a fábrica de Sorocaba passou a processor $100 \mathrm{mil}$ toneladas de produtos em fim de vida por mês, mas há potencial para processar 600 mil (RFID JOURNAL, 2015).

Inúmeras vantagens foram e são obtidas com o SmartWaste, como a redução da emissão de $\mathrm{CO}_{2}$, a economia de água, a diminuição da pegada de carbono e de combustível fóssil sobre manufatura, o transporte e a reciclagem, além de milhões de cartuchos fora de aterros (HP, 2011). 
Atualmente, o programa de reciclagem da HP Brasil atende a $100 \%$ do seu portfólio de produtos por meio da infraestrutura de $L R$, que é estrategicamente distribuída em todo o país para recolhimento e reciclagem de baterias, computadores e impressoras (HP, 2011). Conforme HP (2015a), por meio de suas iniciativas, a empresa foi considerada uma das mais sustentáveis do país no seu setor pelo "Guia Exame de Sustentabilidade 2014" e ganhou o prêmio "Isto É - As Empresas Mais Conscientes". Em 2013, recebeu o "Prêmio Eco Brasil 2013" por suas práticas em sustentabilidade e venceu o "Top Sustentabilidade ADVB" por seu programa de reciclagem HP Planet Partners. Em 2012, a HP ganhou o "Prêmio Greenbest" com seus cartuchos e foi vencedora da categoria "Green do 10. RFID Journal Awards", por apresentar soluções em RFID como gestão do ciclo de vida de seus produtos fabricados no Brasil, por meio do Projeto SmartWaste.

De acordo com o RFID-CoE (2015), o SmartWaste foi reconhecido mundialmente como o projeto mais avançado já realizado, recebendo do líder de mídia, RFID Journal, o prêmio Best RFID Implementation; além disso, foi classificado entre os "TOP 25 Projetos de Inovação Brasileiros", em pesquisa realizada pelo Monitor Group e Revista Exame; e também foi listado entre os top 50 na categoria de Innovation Mastery pelo Gerenciamento de Manufatura e Supply Chain com RFID.

Segundo Kruglianskas e Cuzziol (2014), até o presente a HP Brasil não precisou reestruturar seus programas para se adequar à PNRS. Dos 15 objetivos estabelecidos pela PNRS, 14 são plenamente atendidos pelo programa HP de reciclagem, ao passo que 8 estão vinculados aos produtos e métodos produtivos (Quadro 9). 
Quadro 9 - Objetivos da PNRS que são atendidos com o programa de reciclagem HP

\begin{tabular}{|l|c|c|}
\hline \multicolumn{1}{|c|}{ Objetivos da PNRS } & $\begin{array}{c}\text { Sistema Sinctronics } \\
\text { atende? }\end{array}$ & $\begin{array}{c}\text { Relação direta com o } \\
\text { processo produtivo? }\end{array}$ \\
\hline i - qualidade ambiental & Sim & - \\
\hline ii - redução, reutilização, reciclagem & Sim \\
\hline iii - padrões de produção sustentáveis & Sim & Sim \\
\hline iv - desenvolvimento de tecnologias limpas & Sim & Sim \\
\hline v- redução de volume de resíduos perigosos & Sim \\
\hline vi - fomentar uso de recicláveis e reciclados & Sim & Sim \\
\hline vii - gestão integrada & Sim & - \\
\hline viii - cooperação técnica e financeira & Sim & - \\
\hline ix - capacitação em resíduos sólidos & Sim & - \\
\hline x - regularidade no manejo de resíduos & Sim & - \\
\hline xi - prioridade nas contratações & Viabiliza & - \\
\hline xii - integração de catadores de recicláveis & Sim & - \\
\hline xiii - ciclo de vida do produto & Sim & Sim \\
\hline xiv - melhoria de processos produtivos & Sim & Sim \\
\hline xv - rotulagem ambiental & Sim & Sim \\
\hline
\end{tabular}

Fonte: Ohde (2013)

A HP entende que a PNRS oportuniza o desenvolvimento do setor de eletroeletrônicos e há tempos já se preparava para o cenário atual. Com seu pioneirismo na gestão de resíduos no Brasil, a HP está numa posição vantajosa em relação a seus concorrentes de mercado.

\section{CONSIDERAÇÕES FINAIS}

A partir da Revisão Sistemática da Literatura e do levantamento bibliométrico realizados, foi possível identificar o crescimento do interesse em pesquisas relacionadas aos temas da Logística Reversa, lixo eletrônico e tecnologias de identificação de produtos. Por outro lado, apesar do setor de eletroeletrônicos se preocupar com o reaproveitamento de seus produtos, evidenciou-se a carência de trabalhos que envolvam processos tecnológicos para a Logística Reversa do REEE.

Assim, a pesquisa atingiu seu objetivo ao tratar o assunto do desenvolvimento ambientalmente sustentável, procurando inter-relacionar os temas supracitados e ofereceu um panorama útil aos pesquisadores, contribuindo para a melhor implementação da Política Nacional de Resíduos Sólidos.

Por meio do estudo de caso na HP, pode-se inferir que a RFID e o código de barras são tecnologias úteis e viáveis nas práticas de Logística Reversa do lixo eletrônico. Além disso, podem-se apresentar os principais fatores que motivaram o 
desenvolvimento da RFID na cadeia end-to-end da HP, abrangendo fabricação, distribuição, reparação, logística e reciclagem de seus produtos. Ademais, foi possível identificar os benefícios conquistados com o projeto. Um detalhe a ser destacado é que o SmartWaste é um projeto inovador, de reconhecimento mundial e obteve diversas premiações relacionadas à sustentabilidade e à tecnologia.

A gestão ambientalmente adequada do lixo eletrônico ainda se mostra bastante tímida no Brasil. É preciso que a Logística Reversa ganhe mais espaço nas decisões empresariais e que o controle da tecnologia de identificação de produtos adote ferramentas que garantam eficiência e confiança em toda a cadeia reversa. Para isso, são necessários estudos mais aprofundados a respeito da Logística Reversa do lixo eletrônico e da RFID, para se identificarem fatores de sucesso nos países em desenvolvimento.

Às pesquisas futuras, recomenda-se: i) desenvolver estudos sobre a viabilidade técnica e econômica da aplicação da RFID na cadeia reversa dos produtos das linhas Branca, Marrom e Azul e ii) mapear os problemas mais complexos que ocorrem nas entradas, no processamento e nas saídas em um sistema de manufatura reversa de resíduos eletroeletrônicos, para então se proporem melhores alternativas para sua gestão.

\section{REFERÊNCIAS}

ABDI - AGÊNCIA BRASILEIRA DE DESENVOLVIMENTO INDUSTRIAL. Logística reversa de equipamentos eletroeletrônicos - análise de viabilidade técnica e econômica. Brasília, 2013. http://www.mdic.gov.br/arquivos/dwnl 1367253180.pdf

Estudo para o Fomento do Uso de Etiquetas Inteligentes nos Setores de Comércio e Serviços Logísticos. v.1 - análise comparativa sobre experiências internacionais. Brasília, 2015a.

http://www.abdi.com.br/Estudo/Relatorio\%20Tecnico\%20Etiquetas\%20Inteligentes\%20\%2011122014\%20-\%20Ver04.pdf

Estudo para o Fomento do Uso de Etiquetas Inteligentes nos Setores de

Comércio e Serviços Logísticos. v. 2 - experiências brasileiras. Brasília, 2015b.

http://www.abdi.com.br/Estudo/Estudo Etiquetas Inteligentes - Vol2.pdf

ABINEE - Associação Brasileira da Indústria Elétrica e Eletrônica. A indústria elétrica e eletrônica impulsionando a economia verde e a sustentabilidade. São Paulo, Junho de 2012.

http://www.abinee.org.br/programas/imagens/abinee20.pdf 
ADHIARNA, N. HWANG, Y. M; RHO, J. J. A Two-Dimensional Framework for RFID Adoption and Diffusion: Strategic Implications for Developing Countries. Journal of Technology Management \& Innovation. v.6, n. 2, p.189-201, 2011. http://dx.doi.org/10.4067/S0718-27242011000200013

ADRIANO DA SILVA, L. A.; PIMENTA, H. C. D.; CAMPOS, L. M. S. Logística reversa dos resíduos eletrônicos do setor de informática: realidade, perspectivas e desafios na cidade do Natal-RN. Produção Online, Florianópolis, SC, v.13, n. 2, p. 544-576, abr./jun. 2013. http://dx.doi.org/10.14488/1676-1901.v13i2.1133

ALMEIDA et al. Análise da logística reversa de resíduos de equipamentos eletroeletrônicos (computadores) com base na política nacional de resíduos sólidos. XXXII Encontro nacional de engenharia de produção. Bento Gonçalves, RS, 2012.

http://www.abepro.org.br/biblioteca/enegep2012 TN STO 165962 20121.pdf

ANDRADE, R. O. B.; TACHIZAWA, T.; CARVALHO, A. B. Gestão ambiental: enfoque estratégico aplicado ao desenvolvimento sustentável. 2. Ed. São Paulo: Pearson, 2002.

ANGELES, R. Using the Technology-Organization-Environment Framework and Zuboff's Concepts for Understanding Environmental Sustainability and RFID: Two Case Studies. International Journal of Social, Behavioral, Educational, Economic and Management Engineering, v. 7, n. 11, 2013. scholar.waset.org/1999.10/17339

ARAÚJO et al. Logística reversa no comércio eletrônico: um estudo de caso. Gestão e Produção, São Carlos, v. 20, n. 2, p. 303-320, 2013. http://dx.doi.org/10.1590/S0104-530X2013000200005

AHSAN, K.; SHAH, H. e KINGSTON, P. RFID Applications: An Introductory and Exploratory Study. International Journal of Computer Science Issues, v.7, n.3, p. 1-7, 2010.

http://www.ijcsi.org/articles/RFID-Applications-An-Introductory-and-Exploratory-Study.php

AHSAN, K. RFID Components, Applications and System Integration with Healthcare Perspective. Electrical and Electronic Engineering. Deploying RFID - Challenges, Solutions, and Open Issues, 2011. https://dx.doi.org/doi:10.5772/963

ARIZON PRID TECHOLOGY (YANGZHOU) CO.,LTD. Worldwide RFID UHF Map. Disponível em http://www.ydrfid.com. Acesso em 7 de agosto de 2014.

BACHU, V. K.; SARAM, S.; KUMAS, N. V. S. S. A Review of RFID Technology. International Journal of Engineering Sciences \& Research Technology, v. 2, Issue: 10. p. 2760-2762. October, 2013. http://www.ijesrt.com/issues\%20pdf\%20file/Archives\%202013/Oct-2013/23.pdf

BALDÉ et al. The global e-waste monitor - 2014. United Nations University, IAS - SCYCLE, Bonn, Germany, 2015. http://i.unu.edu/media/unu.edu/news/52624/UNU-1 stGlobal-E-WasteMonitor-2014-large-optimized.pdf

BANZATO, E. Tecnologia da informação aplicada à logística. São Paulo: IMAM, 2005.

BARTHOLOMEU, D. B. e CAIXETA-FILHO, J. V. Logística ambiental de resíduos sólidos. São Paulo: Atlas, 2011.

BATOCCHIO, A. Uma visão geral sobre RFID e áreas de aplicações. X SBAI - Simpósio Brasileiro de Automação Inteligente. São João Del Rei/MG, 2011. http://www.sba.org.br/rsv/SBAl/SBAI2011/92711.pdf 
BERZ, E. L. Predição do funcionamento de sistemas RFID aplicado a crachás inteligentes. Porto Alegre: PUCRS, 2011, 96p. Dissertação de Mestrado (Faculdade de Informática). http://tede.pucrs.br/tde busca/arquivo.php?codArquivo=3393

BHUPTANI, M.; MORADPOUR, S. RFID: implementando o sistema de identificação por radiofrequência. São Paulo: IMAM, 2005.

BRASIL. Lei no 12.305, de 2 de agosto de 2010. Institui a Política Nacional de Resíduos Sólidos. Diário Oficial da República Federativa do Brasil, DF, Seção 1, pág. 03/08/10.

CARVALHO, T. C. M. B.; XAVIER, H. L. Gestão de Resíduos Eletroeletrônicos - Uma abordagem prática para a sustentabilidade. Rio de Janeiro: Elsevier, 2014.

CHUANG, M-L; SHAW, W. H. RFID: Integration Stages in Supply Chain Management. Engineering Management Review, IEEE, p. 80-87. Second Quarter, 2007. http://dx.doi.org/doi:10.1109/EMR.2007.899757

CONTI, L. R. S. Melhoria do sistema de gestão de ferramentais de manutenção aeronáutica utilizando a tecnologia de identificação automática de dados. Itajubá: UNIFEI, 2011, 153p. Dissertação de mestrado (Pós-Graduação em Engenharia de Produção da Universidade Federal de Itajubá). http://saturno.unifei.edu.br/bim/0038667.pdf

CUMMINGS, J. C.; HOLTZ, W. B.; RIDDLE, M.; ULLMAN, D. Modeling and simulation to support risk management in complex environments. Critical Infrastructure Symposium, 2014.

DEPA - Danish Environmental Protection Agency. The potential of RFID-technology to secure information flow between producers of electronics and waste processors. Strandgade 29 DK1401 Copenhagen K Denmark, 2015. http://mst.dk/service/publikationer/publikationsarkiv/2015/jun/rapport-om-rfid-tags/

EPCGLOBAL. <www.gs1.org/epcglobal> Acesso em 10 de agosto de 2014.

EC - European Comission. Case study: Hewlett-Packard (Brazil). The Sectorial E-business Watch. Oxfordstr, Bonn, Germany, outubro de 2008. http://ec.europa.eu/enterprise/archives/ebusiness-watch/studies/case studies/consumer electro.htm

XAVIER et al. A view about RFID technology in Brazil. Technology Management for Global Economic Growth, p.1-9, 18-22 July, 2010. http://ieeexplore.ieee.org/xpls/abs all.jsp?arnumber=5602031

GS1 BRASIL. <http://www.gs1br.org > Acesso em 14 julho de 2014.

Primavera tecnológica. Associação Brasileira de Automação. Revista Brasil em Código. Edição 09. São Paulo, 2013.

Agenda Sustentável. Associação Brasileira de Automação. Revista Brasil em Código. Edição 16. São Paulo, 2015.

GS1. Global user manual. Issue 11, Approved, Mar-2010. <http://www.gs1br.org > Acesso em 15 de julho de 2014.

Regulatory status for using RFID in the EPC Gen 2 band ( 860 to $960 \mathrm{MHz}$ ) of the UHF spectrum. 31 May 2013. Acesso em 11 de agosto de 2014. 
GOLDEMBERG, J.; CORTEZ, C. L. Resíduos sólidos e a logística reversa: o que o empresário do comércio e serviços precisa saber. FECOMERCIOSP. São Paulo, 2014.

http://www.fecomercio.com.br/NoticiaArtigo/Artigo/11014

GONÇALVES, M. E.; MARINS, F. A. S. Logística reversa numa empresa de laminação de vidros: um estudo de caso. Gestão e Produção. v.13, n.3, p. 397 - 410, 2006.

http://dx.doi.org/10.1590/S0104-530X2006000300004

HASHEMI, A.; SARHADDI, A. H.; EMAMI, H. A Review on Chipless RFID Tag Design. Majlesi Journal of Electrical Engineering, v. 7, n. 2, p. 68-75. Jun, 2013.

http://mjee.org/index/index.php/ee/article/view/991

HAYAT, C. Barcode Integration Delivers Big Efficiencies. Vision \& Sensors, v. 52, n. 1; p.19-21, 2013. http://connection.ebscohost.com/c/articles/85935751/barcode-integration-delivers-bigefficiencies

HP - Hewlett-Packard. Disponível em http://www8.hp.com/br/pt/. Acesso em 03 de outubro de 2015a.

Reciclagem de cartuchos de tinta HP originais. Disponível em

http://www.hp.com/latam/br/reciclar/index.html. Acesso em 06 de outubro de 2015b.

Radio Frequency Identification (RFID) at HP. White Paper. Hewlett-Packard Development Company, 5982-4290EN, February, 2004.

Relatório de Sustentabilidade Ambiental HP Brasil, 2011.

HP 2014 Living Progress Report, 2014.

KRUGLIANSKAS, I; CUZZIOL, V. Gestão estratégica da sustentabilidade: experiências brasileiras. $1^{\mathrm{a}}$ ed. Rio de Janeiro: Elsevier, 2014.

LAVEZ, N.; DE SOUZA, V. M.; LEITE, P. R. O papel da logística reversa no reaproveitamento do "REEE" - um estudo no setor de computadores. Gestão Social e Ambiental - RGSA, São Paulo, v.5, n.1, p. 15-32, 2011. http://dx.doi.org/10.5773/rgsa.v5i1.263

LEE, C.K.M; CHAN, T.M. Development of RFID - based Reverse Logistics System. Expert Systems with Applications, v. 36, n. 5, p. 9299-9307, 2009. Doi: 10.1016 / j.eswa.2008.12.002

LEITE, P. R. Logística reversa: meio ambiente e competitividade. 2. Ed. São Paulo: Pearson, 2009.

LEITE, P. R. Logística Reversa e a Política Nacional de Resíduos Sólidos. Tecnologística. Edição 178. p. 90-92. São Paulo, 2010.

LEITE, P. R. et al. O impacto da tecnologia de etiqueta inteligente (RFID) na performance de cadeias de suprimentos - um estudo no Brasil. Jovens Pesquisadores, v. 5, n. 9, p. 101-118, 2008.

LEITE, P. R.; ADERITO SILVA, A. Empresas brasileiras adotam políticas de logística reversa relacionadas com o motivo de retorno e os direcionadores estratégicos? Gestão Social e Ambiental, São Paulo, v. 6, n. 2, p. 79-92, 2012. http://dx.doi.org/10.5773/rgsa.v6i2.501

MARCHESAN, A. M. M.; STEIGLEDER, A. M.; CAPELLI, S. Direito ambiental. 5. edição. Porto Alegre: Verbo Jurídico, 2008.

Revista Produção Online, Florianópolis, SC, v. 16, n. 2, p. 633-677, abr./jun. 2016. 
MARQUES et al. A tecnologia de identificadores de rádio frequência (RFID) na logística interna industrial: pesquisa exploratória numa empresa de usinados para o setor aeroespacial. GEPROS. v. 4, n. 2, p. 109-122, 2009. http://revista.feb.unesp.br/index.php/gepros/article/view/750

MIGUEZ, E. C. Logística reversa como solução para o problema do REEE: benefícios ambientais e financeiros. Rio de Janeiro: Qualitymark, 2012.

NASCIMENTO, E. P. Trajetória da sustentabilidade: do ambiental ao social, do social ao econômico. Estudos Avançados. v. 26, n. 74, p. 51 - 64. São Paulo, 2012.

http://dx.doi.org/10.1590/S0103-40142012000100005

NATUME, R Y.; SANT'ANNA, F. S. P. Resíduos Eletroeletrônicos: um desafio para o desenvolvimento sustentável e a nova lei da Política Nacional de Resíduos Sólidos. 3rd International Workshop | Advances in Cleaner Production. São Paulo, Brazil, 2011. http://www.advancesincleanerproduction.net/third/english/site/downloads.asp

NIKOLAOU, I. E.; EVANGELINOS, K. I.; ALLAN, S. A reverse logistics social responsibility evaluation framework based on the triple bottom line approach. Journal of Cleaner Production, $\mathrm{v}$. 56, p.173-184, 2013. doi: 10.1016/ j.jclepro.2011.12.009

OFFENHUBER, D.; WOLF, M. I.; RATTI, C. Trash track - active location sensing for evaluating ewaste transportation. Waste Management \& Research. v. 31, n. 2, p. 150-159, 2013. http://dx.doi.org/10.1177/0734242X12469822

OHDE, C. Colaboração em logística reversa e reciclagem na indústria elétrica e eletrônica. Fórum Abineetec, 1 a 5 de abril de 2013. Sinctronics, 2013.

OLIVEIRA, B. M. C.; EL-DEIR, S. G. Gestão do REEE na Universidade Federal Rural de Pernambuco. Il Congresso Brasileiro de Gestão Ambiental. Paraná, 2011.

PANDINI, M. SmartWaste: Tracking e-waste through RFID-enabled system. RFID Journal Live! Brasil. Espaço APAS - São Paulo, Brazil, 29 e 30 de novembro de 2012.

PANT, D. E-waste projection using life-span and population statistics. The international journal of life cycle assessment, v. 18, n. 8, p.1465, 2013.

PARK, K. S.; KOH, C. E.; NAM, K. Perceptions of RFID technology: a cross-national study. Industrial Management \& Data Systems, v. 110, n. 5, p. 682-700, 2010. http://dx.doi.org/10.1108/02635571011044722

PEDROSO, M. C.; ZWICKER, R.; SOUZA, C. A. Adoção de RFID no Brasil: Um estudo exploratório. Administração Mackenzie, v. 10, p. 12-36, 2009. http://dx.doi.org/10.1590/S1678$\underline{69712009000100002}$

PEREIRA et al. Logística reversa e sustentabilidade. São Paulo: Cengage Learning, 2013. PSP - PREFEITURA DA CIDADE DE SÃO PAULO. Plano de gestão integrada de resíduos sólidos da cidade de São Paulo. São Paulo, 2014.

QUINTANILHA, L. A gestão sustentável de resíduo eletroeletrônico. Revista Meio Ambiente Industrial, p. 24-39, setembro/outubro, 2009.

RAMANATHAN, R.; BENTLEY, Y.; KO, L. W. L. Investigation of the status of RFID applications in the UK logistics sector. Journal Logistics \& Transport Focus, 2012. 
http://connection.ebscohost.com/c/articles/83411816/investigation-status-rfid-applications-uk$\underline{\text { logistics-sector }}$

REI, A. J. L. RFID versus Código de Barras: da produção à grande distribuição. Portugal. Julho2010, 118p. Dissertação Mestrado (Engenharia Electrotécnica e de Computadores da Faculdade de Engenharia da Universidade do Porto). http://hdl.handle.net/10216/58411

RFID-CoE. Centro de Excelência RFID. www.rfid-coe.com. Acesso em 02 de outubro de 2015. RFID JOURNAL. http://rfidjournal.com/. Acesso em 01 de outubro de 2015.

RFID JOURNAL BRASIL. http://brasil.rfidjournal.com/. Acesso em 03 de outubro de 2015.

RUBIO, S.; JIMÉNEZ-PARRA, B. Reverse Logistics: Overview and Challenges for Supply Chain Management. International Journal of Engineering Business Management. Challenges for Supply Chain Management. p. 6 -12, 2014. http://dx.doi.org/10.5772/58826

SANTINI, A. G. RFID - Radio Frequency Identification: conceitos, aplicabilidades e impactos. Rio de Janeiro: Ciência Moderna, 2008.

SANTOS, R. F. Proposta de um modelo de gestão integrada da Cadeia de suprimentos: aplicação no segmento de eletrodomésticos. 2010. 202f. Tese de Doutorado (Instituto Tecnológico de Aeronáutica). São José dos Campos/SP, 2010.

http://www.bd.bibl.ita.br/tesesdigitais/000565075.pdf

SARTORI, S., LATRÔNICO, F., CAMPOS, L. M. S. Sustentabilidade e desenvolvimento sustentável: uma taxonomia no campo da literatura. Ambiente \& Sociedade - São Paulo v. 17, n. 1, p.1-22, 2014. http://www.scielo.br/scielo.php?pid=S1414-753X2014000100002\&script=sci arttext

SASAKI, Y. RFID e a logística reversa. RFID Journal Brasil, 2013. Disponível em http://brasil.rfidjournal.com Acesso em 10 de maio de 2014.

SCHLUEP, M. Recycling - from e-waste to resources. UNEP - United Nations Environment Programme \& UNU - United Nations University, 2009.

http://www.unep.org/publications/contents/pub details search.asp?ID=4136

SEO, E.S.M.; FINGERMAN, N.N. Sustentabilidade na Gestão de Resíduos Sólidos: Panorama do Segmento EletroEletrônico. InterfaceHS - Saúde, Meio Ambiente e Sustentabilidade, v. 6, n. 3, 2011. http://www.revistas.sp.senac.br/index.php/ITF/article/view/232

SEQUEIRA, R. C. F. S. Automatismo no Processo de Identificação do Produto: RFID vs Código de Barras. Portugal, julho-2010. 92p. Dissertação Mestrado (Engenharia Industrial e Gestão Faculdade de Engenharia da Universidade do Porto).

https://sigarra.up.pt/feup/pt/teses.tese?P aluno $\mathrm{id}=110328 \& p$ processo=17891\&P LANG=0

SINCTRONICS. Transformando resíduos eletroeletrônicos em peças para novos produtos. Fórum Abineetec, 23 a 27 de março de 2015. Sinctronics, 2015.

TAVARES, D. M.; BACHEGA, S. J. CAURIN, G. A. P. Architecture proposal for the use of QR code in supply chain management; Produção Online. Florianópolis, SC, v.12, n. 1, p. 73-90, 2012. http://dx.doi.org/10.14488/1676-1901.v12i1.738

VALLE, R.; SOUZA, R. G. Logística reversa: processo a processo. São Paulo: Atlas, 2014. 
VICENTE, S. C. S.; FERREIRA, G. T. C. Logística reversa de resíduos sólidos: uma análise crítica dos desafios impostos pela Lei 12.305/10. XIV Simpósio de Administração da Produção, Logística e Operações Internacionais, 2011.

WANT, R. An Introduction to RFID Technology. IEEE Pervasive Computing. v.5, n.1, p. 25-33. 2006. http://dx.doi.org/10,1109 / MPRV.2006.2

XAVIER, L. H.; CORREAA, H. L. Sistemas de logística reversa - criando cadeias de suprimento sustentáveis. São Paulo: Atlas, 2013.

ZHU, X.; MUKHOPADHYAY, S. K. e KURATA, H. A review of RFID technology and its managerial applications in different industries. Journal of Engineering and Technology Management, v. 29, n. 1, p. 15-167, 2012. http://dx.doi.org/10.1016/j.jengtecman.2011.09.011

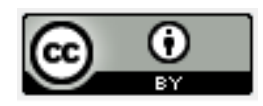

Artigo recebido em 11/05/2015 e aceito para publicação em 31/10/2015

DOI: http://dx.doi.org/ 10.14488/1676-1901.v16i2.2049 